\title{
Identification of Glioblastoma Phosphotyrosine-Containing Proteins with Two-Dimensional Western Blotting and Tandem Mass Spectrometry
}

\author{
Tianyao Guo, ${ }^{1,2,3}$ Xiaowei Wang, ${ }^{1,2,3}$ Maoyu Li, ${ }^{1,2,3}$ Haiyan Yang, ${ }^{1,2,3}$ Ling Li, \\ Fang Peng, ${ }^{1,2,3}$ and Xianquan Zhan ${ }^{1,2,3,4}$ \\ ${ }^{1}$ Key Laboratory of Cancer Proteomics of Chinese Ministry of Health, Xiangya Hospital, Central South University, \\ 87 Xiangya Road, Changsha, Hunan 410008, China \\ ${ }^{2}$ Hunan Engineering Laboratory for Structural Biology and Drug Design, Xiangya Hospital, Central South University, \\ 87 Xiangya Road, Changsha, Hunan 410008, China \\ ${ }^{3}$ State Local Joint Engineering Laboratory for Anticancer Drugs, Xiangya Hospital, Central South University, \\ 87 Xiangya Road, Changsha, Hunan 410008, China \\ ${ }^{4}$ The State Key Laboratory of Medical Genetics, Central South University, 88 Xiangya Road, Changsha, Hunan 410008, China \\ Correspondence should be addressed to Xianquan Zhan; yjzhan2011@gmail.com
}

Received 11 June 2014; Revised 25 August 2014; Accepted 25 August 2014

Academic Editor: Fa-Yun Che

Copyright (C) 2015 Tianyao Guo et al. This is an open access article distributed under the Creative Commons Attribution License, which permits unrestricted use, distribution, and reproduction in any medium, provided the original work is properly cited.

\begin{abstract}
To investigate the presence of, and the potential biological roles of, protein tyrosine phosphorylation in the glioblastoma pathogenesis, two-dimensional gel electrophoresis- (2DGE-) based Western blotting coupled with liquid chromatographyelectrospray ionization-tandem mass spectrometry (LC-ESI-MS/MS) analysis was used to detect and identify the phosphotyrosine immunoreaction-positive proteins in a glioblastoma tissue. MS/MS and Mascot analyses were used to determine the phosphotyrosine sites of each phosphopeptide. Protein domain and motif analysis and systems pathway analysis were used to determine the protein domains/motifs that contained phosphotyrosine residue and signal pathway networks to clarify the potential biological functions of protein tyrosine phosphorylation. A total of 24 phosphotyrosine-containing proteins were identified. Each phosphotyrosine-containing protein contained at least one tyrosine kinase phosphorylation motif and a certain structural and functional domains. Those phosphotyrosine-containing proteins were involved in the multiple signal pathway systems such as oxidative stress, stress response, and cell migration. Those data show 2DGE-based Western blotting, MS/MS, and bioinformatics are a set of effective approaches to detect and identify glioblastoma tyrosine-phosphorylated proteome and to effectively rationalize the biological roles of tyrosine phosphorylation in the glioblastoma biological systems. It provides novel insights regarding tyrosine phosphorylation and its potential role in the molecular mechanism of a glioblastoma.
\end{abstract}

\section{Introduction}

Tyrosine phosphorylation that is an addition of phosphogroup $\left(-\mathrm{HPO}_{3}\right.$ to $-\mathrm{OH}$ or $-\mathrm{H}_{3} \mathrm{PO}_{4}$ to $\left.-\mathrm{NH}_{2}\right)$ to the tyrosine residue is a type of protein posttranslational modification that plays key roles in the signal transduction and participates in many physiological and pathological processes such as growth, proliferation, differentiation, aging, cancer, and inflammatory diseases [1-3]. Tyrosine phosphorylation and dephosphorylation are a reversibly dynamic mechanism that is regulated by protein tyrosine kinases (PTKs) and protein tyrosine phosphatases (PTPs) [4]. Moreover, tyrosine kinase phosphorylation generally occurs within a consensus pattern/motif [R/K]-x(2)-[D/E]-x(3)-Y or [R/K]-x(3)-[D/E]$\mathrm{x}(2)-\mathrm{Y}(\mathrm{Y}=$ the phosphorylation site) [5-7]. Currently, 518 human protein kinase genes [8] including 90 known tyrosine kinases that include 58 receptor tyrosine kinases (RTKs) $[9,10]$ and 107 tyrosine phosphatases [11] have been discovered for potential targets of anticancer drugs, most tyrosine kinases are regulated negatively and only activated 
under certain conditions [8], and interestingly tyrosine kinases accounting for $0.3 \%$ of genome contribute to a large proportion $(30 \%)$ of 100 known dominant oncogenes $[10,12]$. Tyrosine phosphorylation (accounting for only $\sim 0.05 \%$ ) is a low abundance event in the phosphoproteome relative to phosphorylation at the serine (accounting for $~ 90 \%$ ) and threonine (accounting for $\sim 10 \%$ ) residues in eukaryotic cells $[1,3,10,13]$. However, characterization of altered modification and functional activities of phosphotyrosine-containing proteins in different types of cancers has helped in the discovery of specific tyrosine kinase inhibitors to treat a cancer $[9,14]$. Thus, it emphasizes the scientific importance of investigating phosphotyrosine-containing proteins in a cancer.

The most common characteristics of glioblastoma are highly invasive growth and aggressive infiltration into surrounding normal brain, which causes the failure of current therapies to control glioblastoma, with a median survival of 9-12 months in spite of the improvement of the current therapies such as surgery, radiotherapy, and chemotherapy [15]. The molecular mechanisms of glioblastoma remain unclear. It is necessary to discover novel biomarkers for novel therapeutic strategy to control its invasive growth. Many studies have indicated that tyrosine phosphorylation is extensively associated with pathophysiological processes of glioma including angiogenesis [16-21], immune response [22], and invasive growth and migration [23-27]. Tumor angiogenesis is an important reason why glioblastoma is capable of highly invasive growth and aggressive infiltration. Many positive and negative regulating factors of angiogenesis are involved in the tyrosine phosphorylation [16-21], such as vascular endothelial growth factor (VEGF) and its receptor (VEGFR) [16, 17, 21, 28], epidermal growth factor (EGF) and its receptor (EGFR) $[15,19,20,29-32]$, platelet-derived growth factor (PDGF) and its receptor (PDGFR) [29, 33], leucine-rich repeat C4 (LRRC4) [18], the uPA/uPAR system [34], ERK1/2 signaling [35], and the focal adhesion kinase signaling pathway $[36,37]$. A series of protein kinases associated with glioma are studied including RTK (EGFR, ErbB2, ErbB3, IGF-IR, and KIT) [30-32, 38-40], Lyn kinase/Src kinase [41], Akt and focal adhesion kinase [27, 36, 37, 42, 43], Janus kianse [44], ABL2/ARG tyrosine kinase [45], ephrin family [46, 47], Fyn related kinase (FRK) [48], STAT-3 [49] and STAT-6 [23], Mer receptor tyrosine kinase [25], and VEGFR-2 tyrosine kinase [28]. The documented literature demonstrates the importance of tyrosine phosphorylation in the pathogenesis of glioma. However, the large-scale detection and identification of phosphotyrosine-containing proteins in glioblastoma are rarely reported. The tyrosinephosphorylated proteomics analysis is necessary to detect the phosphotyrosine-containing proteins and clarify the potential biological functions of tyrosine phosphorylation in glioblastoma.

MS/MS-identification of phosphotyrosine-containing proteins is hindered by the low abundance of phosphotyrosine-containing proteins [50], and MS-identification of phosphopeptides is also complicated by ion suppression effects because of the high background of nonphosphorylated peptides. Enrichment of phosphotyrosine-containing proteins is essential prior to MS analysis. 2DGE in combination with antiphosphotyrosine antibody is an effective method to relatively enrich and detect phosphotyrosine-containing proteins. In this study, we investigated presence of and the potential biological roles of the tyrosine phosphorylation in a protein in a glioblastoma tissue. Anti-phosphotyrosine antibodies were used to detected phosphotyrosine-containing proteins in a polyvinylidene fluoride (PVDF) membrane that were transferred from a $2 \mathrm{D}$ gel with the separated glioblastoma proteins. LC-MS/MS was used to determine the amino acid sequence of those phosphotyrosine-containing proteins that were contained in the immunoreactive-positive $2 \mathrm{D}$ gel spots. The protein and phosphotyrosine sites were determined with Mascot software, and the biological functions and pathway networks involved in the modified proteins were achieved with systems pathway analysis. These results provided a platform to investigate phosphotyrosine proteome in human glioblastoma and to explore its potential biological roles of tyrosine phosphorylation in the glioblastoma.

\section{Materials and Methods}

2.1. Glioblastoma Tissue. A glioma tissue (male, 57 years old) was obtained from Department of Neurosurgery of Xiangya Hospital, China, and approved by the Xiangya Hospital Medical Ethics Committee of Central South University, China. The glioma tissue was removed from neurosurgery and immediately stored at liquid nitrogen $\left(-196^{\circ} \mathrm{C}\right)$. A portion of glioma tissues was used for pathological diagnosis and was diagnosed as grade IV glioblastoma, and the rest was stored in $-80^{\circ} \mathrm{C}$.

2.2. Protein Extraction. A portion of a human glioblastoma tissue $(430 \mathrm{mg})$ was washed with $0.9 \% \mathrm{NaCl}(3 \mathrm{~mL}, 5 \times)$ to remove contaminated blood fully and then was fully grilled in liquid nitrogen. A volume $(2 \mathrm{~mL})$ of protein extraction buffer $(7 \mathrm{~mol} / \mathrm{L}$ urea, $2 \mathrm{~mol} / \mathrm{L}$ thiourea, $40 \mathrm{~g} / \mathrm{L} 3-$ (3-cholamidopropyl)dimethylammonio-1-propanesulfonate (CHAPS), $100 \mathrm{mmol} / \mathrm{L}$ dithiothreitol (DTT), $5 \mathrm{~mL} / \mathrm{L}$ IPG buffer $\mathrm{pH} 3-10 \mathrm{NL}$, and $100 \mu \mathrm{L}$ of phosphatase inhibitor cocktail (Sigma)) was added and mixed. The mixture was vortexed $(2 \mathrm{~h})$ on the ice and centrifuged $(1,5000 \times \mathrm{g}, 15 \mathrm{~min})$. The supernatant was centrifuged again $(1,5000 \times \mathrm{g}, 15 \mathrm{~min})$. The supernatant was used as the protein extract and for determination of protein concentration $(11.8 \mu \mathrm{g} / \mu \mathrm{L})$ with a Bio-Rad 2D Quant kit (Bio-Rad). For an $18 \mathrm{~cm}$ immobilized pH gradient (IPG) strip pH 3-10 NL (GE healthcare), a total of $160 \mu \mathrm{g}(13.6 \mu \mathrm{L})$ of protein extract were fully mixed with $236.4 \mu \mathrm{L}$ of protein extraction buffer $(7 \mathrm{~mol} / \mathrm{L}$ urea, $2 \mathrm{~mol} / \mathrm{L}$ thiourea, $40 \mathrm{~g} / \mathrm{L}$ CHAPS, $100 \mathrm{mmol} / \mathrm{L}$ DTT, $5 \mathrm{~mL} / \mathrm{L}$ IPG buffer $\mathrm{pH} 3-10 \mathrm{NL}$, and a trace of bromphenol blue) and $110 \mu \mathrm{L}$ of rehydration buffer $(7 \mathrm{~mol} / \mathrm{L}$ urea, $2 \mathrm{~mol} / \mathrm{L}$ thiourea, $40 \mathrm{~g} / \mathrm{L}$ CHAPS, $60 \mathrm{mmol} / \mathrm{L}$ DTT, $5 \mathrm{~mL} / \mathrm{L}$ IPG buffer $\mathrm{pH}$ 3-10 NL, and a trace of bromophenol blue). The mixture was centrifuged $(1,5000 \times \mathrm{g}, 15 \mathrm{~min})$. The supernatant was centrifuged again $(1,5000 \times \mathrm{g}, 15 \mathrm{~min})$. The supernatant is called the "protein sample solution." 


\subsection{Two-Dimensional Gel Electrophoresis}

2.3.1. First Dimension-Isoelectric Focusing (IEF). The precast IPG strips $(\mathrm{pH} 3-10 \mathrm{NL} ; 180 \times 3 \times 0.5 \mathrm{~mm})$ and $18 \mathrm{~cm} \mathrm{IPG}$ strip holder were used for IEF on an IPGphor instrument (GH Healthcare) to separate an aliquot $(350 \mu \mathrm{L})$ of the protein sample solution that contained $160 \mu \mathrm{g}$ proteins. The IPG strip was rehydrated overnight $(\sim 18 \mathrm{~h})$, followed by IEF $\left(20^{\circ} \mathrm{C}\right)$ under a running parameter (a gradient at $250 \mathrm{~V}$ and $1 \mathrm{~h}$ for $125 \mathrm{Vh}$, a gradient at $1000 \mathrm{~V}$ and $1 \mathrm{~h}$ for $500 \mathrm{Vh}$, a gradient at $8,000 \mathrm{~V}$ and $1 \mathrm{~h}$ for $4,000 \mathrm{Vh}$, a step and hold at $8,000 \mathrm{~V}$ and $4 \mathrm{~h}$ for $32,000 \mathrm{Vh}$, and a step and hold at $500 \mathrm{~V}$ and $0.5 \mathrm{~h}$ for $250 \mathrm{Vh}$ ) to achieve a final $36,875 \mathrm{Vh}$ and $\sim 7.5 \mathrm{~h}$ run. After IEF, the IPG strip was processed to the second-dimensional electrophoresis.

\subsubsection{Second Dimension-Sodium Dodecyl Sulfate-Polyacryl-} amide Gel Electrophoresis (SDS-PAGE). An Ettan DALT II system (Amersham Pharmacia Biotech; analyze up to 12 gels at a time) was used. The $12 \%$ PAGE resolving gel $(250 \times$ $215 \times 1.0 \mathrm{~mm})$ was cast with an Ettan TM DALTsix multigel caster (Amersham BioSciences) that can cast up to 12 gels at a time. The resolving-gel solution for 3 gels was made by mixing $90 \mathrm{~mL}$ of $400 \mathrm{~g} / \mathrm{L}$ acrylamide/bisacrylamide (29:1 by weight; cross-linking ratio $=3.3 \%), 75 \mathrm{~mL}$ of $1.5 \mathrm{~mol} / \mathrm{L}$ tris- $\mathrm{HCl} \mathrm{pH} \mathrm{8.8,} 135 \mathrm{~mL}$ of distilled and deionized water, $1.5 \mathrm{~mL}$ of $100 \mathrm{~g} / \mathrm{L}$ ammonia persulfate, and $75 \mu \mathrm{L}$ of tetramethylethylenediamine (TEMED). The IPG strip with the protein sample was equilibrated in a reducing equilibrium buffer $(10 \mathrm{~mL} ; 15 \mathrm{~min})$ that contained $375 \mathrm{mmol} / \mathrm{L}$ Trish $\mathrm{pH}$ 8.8, 6 mol/L urea, $20 \mathrm{~g} / \mathrm{L} \mathrm{SDS,} 200 \mathrm{~mol} / \mathrm{L}$ glycerol, $20 \mathrm{~g} / \mathrm{L}$ DTT, and a trace of bromphenol blue. The IPG strip was then equilibrated in an alkylation equilibrium solution (10 $\mathrm{mL} ; 15 \mathrm{~min})$ that contained $25 \mathrm{~g} / \mathrm{L}$ iodoacetamide instead of $20 \mathrm{~g} / \mathrm{L}$ DTT. A boiled solution containing $10 \mathrm{~g} / \mathrm{L}$ low-molecular-weight agarose in the SDS electrophoresis buffer that contained $192 \mathrm{mmol} / \mathrm{L}$ glycine, $25 \mathrm{mmol} / \mathrm{L}$ Tris, and $1 \mathrm{~g} / \mathrm{L}$ SDS was used to seal the equilibrated IPG strip to the top of the resolving gel. Second-dimensional electrophoresis was performed in $10 \mathrm{~L}$ of tris-glycine-SDS electrophoresis buffer that contained $25 \mathrm{mmol} / \mathrm{L}$ tris-base, $192 \mathrm{mmol} / \mathrm{L}$ glycine, and $1 \mathrm{~g} / \mathrm{L} \mathrm{SDS}$ with the following conditions: constant $2.5 \mathrm{~W} /$ gel for $30 \mathrm{~min}$ and then constant $10 \mathrm{~W} /$ gel for $340 \mathrm{~min}$.

2.3.3. Silver Staining of Proteins. The 2DGE-separated protein spots were visualized with a modified silver-staining method [51]. The procedure was that (i) the gel was fixed in $250 \mathrm{~mL}$ of $50 \% \mathrm{v} / \mathrm{v}$ methanol and 5\% v/v acetic acid (20 min), washed in $250 \mathrm{~mL}$ of $50 \% \mathrm{v} / \mathrm{v}$ methanol $(10 \mathrm{~min})$, and washed in deionized water (10 min); (ii) the gel was sensitized in $250 \mathrm{~mL}$ of $0.02 \% \mathrm{w} / \mathrm{v}$ sodium thiosulfate $(1 \mathrm{~min})$ and washed with deionized water ( $1 \mathrm{~min}, 2$ times); (iii) the gel was silverstained $(20 \mathrm{~min})$ in $250 \mathrm{~mL}$ of $0.1 \% \mathrm{w} / \mathrm{v}$ silver nitrate plus $200 \mu \mathrm{L} \mathrm{37 \%} \mathrm{v/v} \mathrm{formaldehyde} \mathrm{and} \mathrm{washed} \mathrm{with} \mathrm{deionized}$ water (1 min, 2 times); (iv) the gel was developed in $250 \mathrm{~mL}$ of $3 \% \mathrm{w} / \mathrm{v}$ sodium carbonate with $100 \mu \mathrm{L} 37 \% \mathrm{v} / \mathrm{v}$ formaldehyde until the desired intensity of staining occurs (usually ca. $3 \mathrm{~min}$ ); (v) the development was stopped in $250 \mathrm{~mL}$ of $5 \%$ $\mathrm{v} / \mathrm{v}$ acetic acid (10 $\mathrm{min})$, and then the gel was washed (5 min) in deionized water and was stored in glycerol $(250 \mathrm{~mL}, 8.8 \%$ $\mathrm{v} / \mathrm{v})$.

2.4. Western Blotting. The proteins separated with 2DGE were transferred to a PVDF membrane $\left(0.8 \mathrm{~mA} / \mathrm{cm}^{2} ; 1 \mathrm{~h}\right.$, $40 \mathrm{~min}$ ) with a Pharmacia Biotech Nova Blot semidry transfer instrument. The PVDF membrane with the proteins was blocked $(1 \mathrm{~h})$ with a volume $(100 \mathrm{~mL})$ of $0.3 \%$ bovine serum albumin/tris-buffered saline with $0.1 \%$ sodium azide and $0.1 \%$ Tween-20 (BSA/TBST). The BSA-blocked PVDF membrane was incubated $\left(5 \mathrm{~h}, 4^{\circ} \mathrm{C}\right)$ with a mouse anti-human phosphotyrosine antibody (Catalogue number MAB3109, Millipore, USA) that was diluted $(1: 1000=\mathrm{v}: \mathrm{v})$ in a $0.3 \%$ BSA/TBST solution. After completion of the incubation with the primary antibody, the membrane was washed with the TBST solution $(100 \mathrm{~mL} ; 5 \mathrm{~min} \times 3)$. The secondary antibody, horse anti-mouse horseradish peroxidase- (HRP-) linked IgG that was purchased from Cell Signaling Technology Inc., USA (Catalogue number 7076), was diluted $(1: 2000=\mathrm{v}: \mathrm{v})$ in a $0.3 \% \mathrm{BSA} / \mathrm{TBST}$ solution and was added to the blots ( $1 \mathrm{~h}$, room temperature). The membrane was washed with TBST $(100 \mathrm{~mL} ; 10 \mathrm{~min} \times 3)$, and phosphotyrosine proteins were visualized with ChemiDoc XRS imaging system (Bio Rad, CA, USA). A parallel negative-control experiment was performed to detect any cross-reactivity of the secondary antibody. For the negative-control experiment (the primary antibody was not added), the entire procedure was the same as the Western blotting. The 2DGE gel, after transferring proteins to PVDF membrane, was silver-stained in the same way as described above to detect any remained proteins on the gel for determination of the efficiency of the protein transfer.

2.5. Image Analysis of a $2 \mathrm{D} \mathrm{Gel}$ and of Western Blotting. The scanned images of the silver-stained $2 \mathrm{D}$ gels and of the visualized Western blot membranes were input to a PDQuest system (BioRad, version 7.1, Hercules, CA) to generate the synthetic image that contained the Gaussian spots (Gaussian image) with a defined volume (volume $=$ optical density $(\mathrm{OD}) \times$ width $(\mathrm{mm}) \times$ length $(\mathrm{mm}))$ and quality [52]. All subsequent spot-matching and analysis steps were performed on the Gaussian spots. In order to minimize the effect of any experimental factor on a spot volume, each spot volume was normalized to the total optical density in each gel image [52].

2.6. Determination of Phosphotyrosine-Containing Proteins. The 2D gel spots corresponding to the phosphotyrosinepositive Western blot spot were excised, and the proteins that were contained in 2D gel spots were digested in gel with trypsin [48]. The tryptic peptide mixture was purified with a ZipTipC18 microcolumn (Catalogue number ZTC18S096, Millipore, USA), according to the methods recommended by the manufacturer. For LC-ESI quadrupole time of flight (LC-ESI-qTOF) MS/MS analysis, the purified tryptic peptide mixture was eluted with $6 \mu \mathrm{L}$ of $850 \mathrm{~mL} / \mathrm{L}$ acetonitrile plus $1 \mathrm{~mL}$ of trifluoroacetic acid (10 cycles) and the elute was airdried. Before analysis, the dried tryptic peptide mixture was redissolved in $6 \mu \mathrm{L}$ of $50 \mathrm{~mL} / \mathrm{L}$ acetonitrile plus $1 \mathrm{~mL} / \mathrm{L}$ formic acid. The purified peptide mixture was subjected to LC-ESIqTOF MS/MS analysis. Briefly, the tryptic peptides from 2D 
gel spots were loaded onto a C18 precolumn for concentrations and fast desalting and then eluted to the reversedphase column for separation. MS/MS spectra were performed in data-depended mode in which up to four precursor ions above an intensity threshold of 7 counts/seconds (cps) were selected for MS/MS analysis from each survey scan. The obtained MS/MS data were used for protein database searching.

For MS/MS database searching, the peptide sequence tag format file that was generated from MS/MS data with MassLynx version 4.0 software was input into the Mascot search engine to search protein against the Swiss-Prot database (release date December 1, 2013; 541954 sequences; 192668437 residues; Homosapiens 20274 sequences). A mass tolerance of $0.3 \mathrm{Da}$ for both parent (MS) and fragmented (MS/MS) ions, allowance for up to one trypsin miscleavage, fixed amino acid modification consisting of cysteine carbamidomethylation, variable amino acid modifications consisting of methionine oxidation, and tyrosine phosphorylation were used. MS/MS ion score threshold was determined to produce a false-positive rate less than $5 \%$ for a significant hit $(P<0.05)$. The false-positive rate was calculated with $2 *$ reverse/(reverse + forward)/100. In the current study, the least MS/MS ion score threshold was 35 and a false-positive rate was approximately $3.1 \%$. Each protein was determined with MS/MS-based amino acid sequences. If protein was identified with only one peptide, its MS/MS spectrum was further checked manually. Each phosphotyrosine-containing peptide was checked manually. Each manual check must consider those factors: high-quality MS/MS spectrum with good signal-to-noise ratio, matched main ion peaks, a good b- or y-ion series, a high intensity of the corresponding precursor ion, the corresponding good LC peaks, and so forth. Also, a blank gel on the margin on a 2D gel was analyzed in parallel to remove any contaminated proteins including trypsin and keratin from the statistically significant results based the MS/MS protein database searching.

Because tyrosine phosphorylation commonly occurs within tyrosine kinase phosphorylation motif, each MS/MSderived protein sequence was input into the ScanProsite program (http://prosite.expasy.org/scanprosite) to determine its protein domains and tyrosine kinase phosphorylation motifs. For the protein without an MS/MS-characterized phosphotyrosine site, it must contain a tyrosine kinase phosphorylation motif to be determined as a phosphotyrosine immune-positive protein.

2.7. Bioinformatics Analysis. Gene-ontology (GO) analysis was used to get more insight on the biological significance of phosphotyrosine-containing proteins with exploring the relationship between the biological terms and associated genes using the NIH-DAVID software (version 6.7, http://david .abcc.ncifcrf.gov/summary.jsp). GO terms with computed $P$ value of less than 0.05 were considered as significantly enriched terms. Homosapiens were selected to limit annotations. Three structured ontologies were chosen to allow the description of biological process, molecular function, and cellular component. Phosphotyrosine-containing proteins were divided into different clusters according to biological function. The proteins within a cluster were close from a biological perspective and correspondingly far from the proteins in other clusters. Moreover, the Swiss-Prot accession numbers of phosphotyrosine-containing proteins were saved as a text file that was input into Cytoscape version 3.0.2 (http://www.cytoscape.org), BiNGO plugin 2.44 downloaded from Cytoscape manage plugin was used to analyze the enriched biological processes and molecular functions, and CytoKegg plugin was used to mine the signaling pathway networks that involved the phosphotyrosine-containing proteins.

Ingenuity pathway analysis (IPA) was used to obtain further insight into potential cellular pathways that might be modified as a result of protein changes identified in this present study. IPA automatically generated networks of gene, protein, small molecule, drug, and disease associations on the basis of "hand-curated" data held in a proprietary database. The identifiers (Swiss-Prot identification number) of phosphotyrosine-containing proteins were uploaded as an Excel spreadsheet file into the Ingenuity software (Ingenuity Systems, Redwood City, CA, USA). Each human identification number was mapped to its corresponding molecule in the ingenuity pathway knowledge base. The statistically significant signaling pathway networks, canonical pathways, biofunctions, and toxfunctions were generated to involve those phosphotyrosine-containing proteins and address the effects of protein tyrosine phosphorylation on those biological pathway systems. Each network, pathway, biofunction, and toxfunction was presented as a graph that indicated the molecular relationship between proteins.

\section{Results and Discussion}

3.1. DGE-Based Western Blot Detection of PhosphotyrosineContaining Proteins. Ca. 900 protein spots were detected in each silver-stained 2D gel. Most protein spots were distributed within a region of $\mathrm{pI} 4-8$ and $M_{r} 15-100 \mathrm{kDa}$. Those phosphotyrosine immunopositive proteins that were transferred onto a PVDF membrane were detected with an antihuman phosphotyrosine antibody (Figure 1). Moreover, a parallel negative-control experiment was carried out to determine any cross-reactivity of secondary antibody. Figure 1(a) shows the silver-stained 2D gel image before proteins were transferred onto a PVDF membrane. Figure 1(b) shows the corresponding silver-stained 2D gel image after proteins were transferred onto a PVDF membrane and demonstrates that at least $92 \%$ proteins $[(900-70) / 900]$ were transferred onto the PVDF membrane. Figure 1(c) shows the Western blot image with the labeled positive phosphotyrosine-immunoreactivity, 51 phosphotyrosine immunopositive Western blot spots were detected, and the corresponding silver-stained protein spots were labeled in Figure 1(a). Figure 1(d) shows there was no cross-reactivity of secondary antibody to further confirm the positive Western blot spots in Figure 1(c).

3.2. LC-ESI-MS/MS Characterization of PhosphotyrosineContaining Proteins. The proteins that were contained in each $2 \mathrm{D}$ gel spot corresponding to the positive phosphotyrosine immunoreactivity were excised and subjected to 


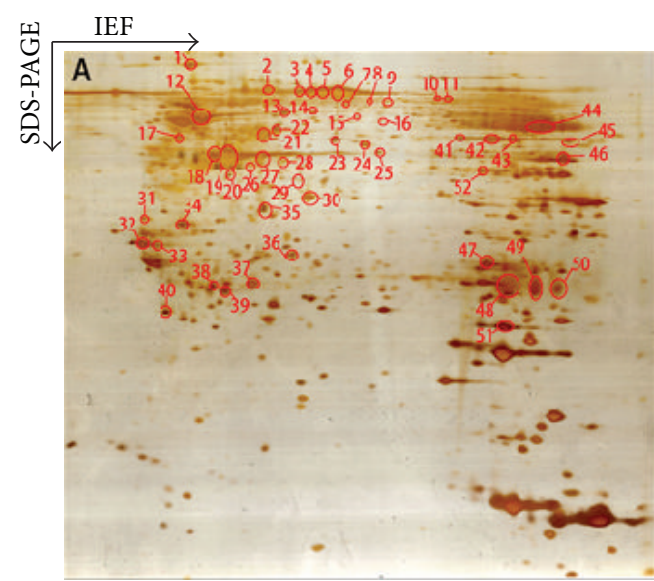

(a)

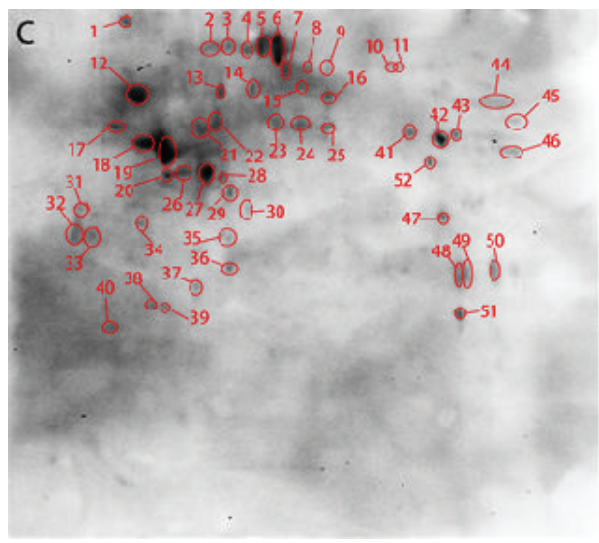

(c)

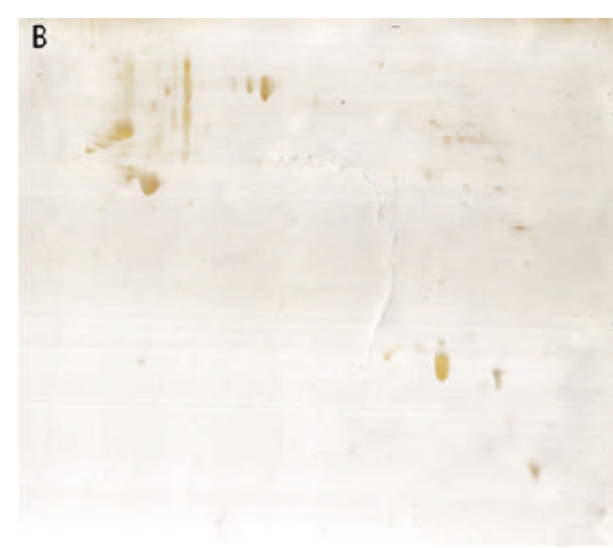

(b)

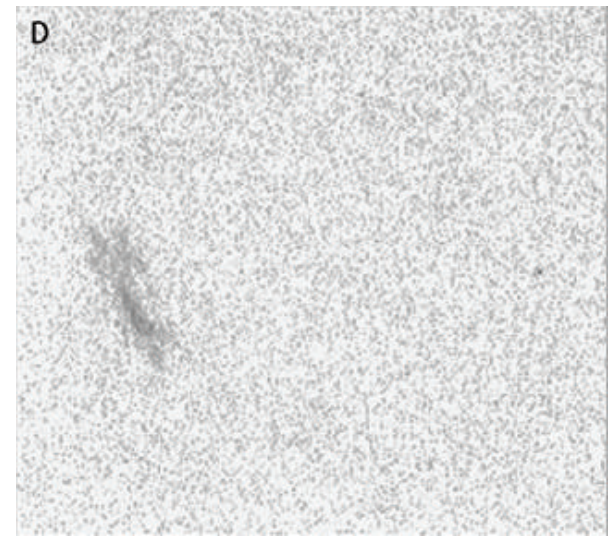

(d)

FIGURE 1: Two-dimensional gel electrophoresis-based Western blot analysis of antiphosphotyrosine proteins in a glioblastoma tissue (160 $\mu \mathrm{g}$ protein per 2D gel). (a) Silver-stained image on a 2D gel before transfer of proteins to a PVDF membrane. (b) Silver-stained image on a 2D gel after transfer of proteins to a PVDF membrane. (c) Western blotting image of antiphosphotyrosine proteins (antiphosphotyrosine antibodies + secondary antibody). (d) Negative control of Western blotting to show the cross-reaction of the secondary antibody (only the secondary antibody, no antiphosphotyrosine antibody).

in-gel digestion with trypsin and purification of tryptic peptides, followed by LC-ESI-MS/MS analysis. The protein and phosphotyrosine site were determined with MS/MS data. Those proteins without MS/MS-characterized phosphotyrosine site were subjected to the ScanProsite analysis to determine their tyrosine kinase phosphotyrosine motifs. In order to consolidate the protein with a phosphotyrosineimmunoreactivity, at least one tyrosine kinase phosphotyrosine motif was contained in that protein amino acid sequence. A total of 36 proteins were identified with MS/MS from 51 phosphotyrosine immunopositive spots (Tables 1 and 2 and Supplemental Table 1 in Supplementary Material available online at http://dx.doi.org/10.1155/2015/134050). In order to consolidate the identification of phosphotyrosinecontaining proteins, 12 proteins without predicted Tyrphosphomotif and without MS/MS-characterized phosphotyrosine sites (Supplemental Table 1) were considered as uncertain phosphotyrosine-containing proteins. Thus, a total of 24 phosphotyrosine-containing proteins were identified in a glioblastoma tissue (Tables 1 and 2). Of them, 15 positive phosphotyrosine-immunoreactivity proteins were identified and summarized in Table 1, and 9 phosphoproteins with MS/MS-characterized phosphotyrosine sites were identified and summarized in Table 2.

Table 1 contained the spot number, Swiss-Prot access number, protein name, molecular weight, pI, Mascot score, the number of matched unique peptides, and tyrosine kinase phosphorylation motifs; those phosphotyrosine-containing proteins were heat shock protein 90 alpha, heat shock protein 90 beta, heat shock $70 \mathrm{kDa}$ protein $1 \mathrm{~A} / 1 \mathrm{~B}$, tubulin alpha$1 \mathrm{~A}$ chain, tubulin alpha-1B chain, tubulin alpha-8 chain, cytoplasmic actin 1, glial fibrillary acidic protein, betaactin-like protein 2, L-lactate dehydrogenase B chain, 143-3 protein epsilon, annexin A5, apolipoprotein A-I, and alpha-enolase. Table 2 contained the spot number, Swiss-Prot access number, protein name, phosphotyrosine-containing peptide sequence, peptide mass, Mascot ion score, and tyrosine kinase phosphorylation motifs; those phosphotyrosinecontaining proteins were receptor-type tyrosine-protein phosphatase S, Arf-GAP with Rho-GAP domain, ANK repeat and $\mathrm{PH}$ domain-containing protein 1 , centrosomal 


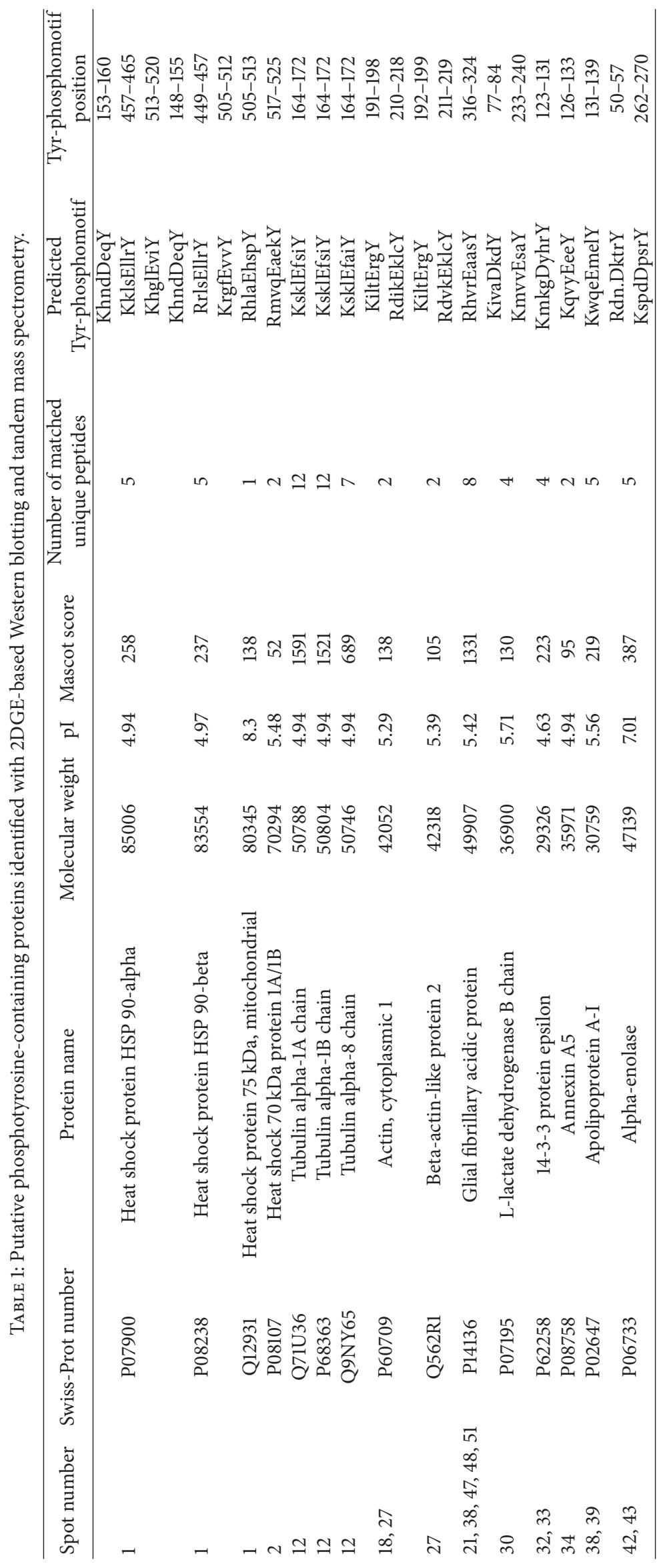




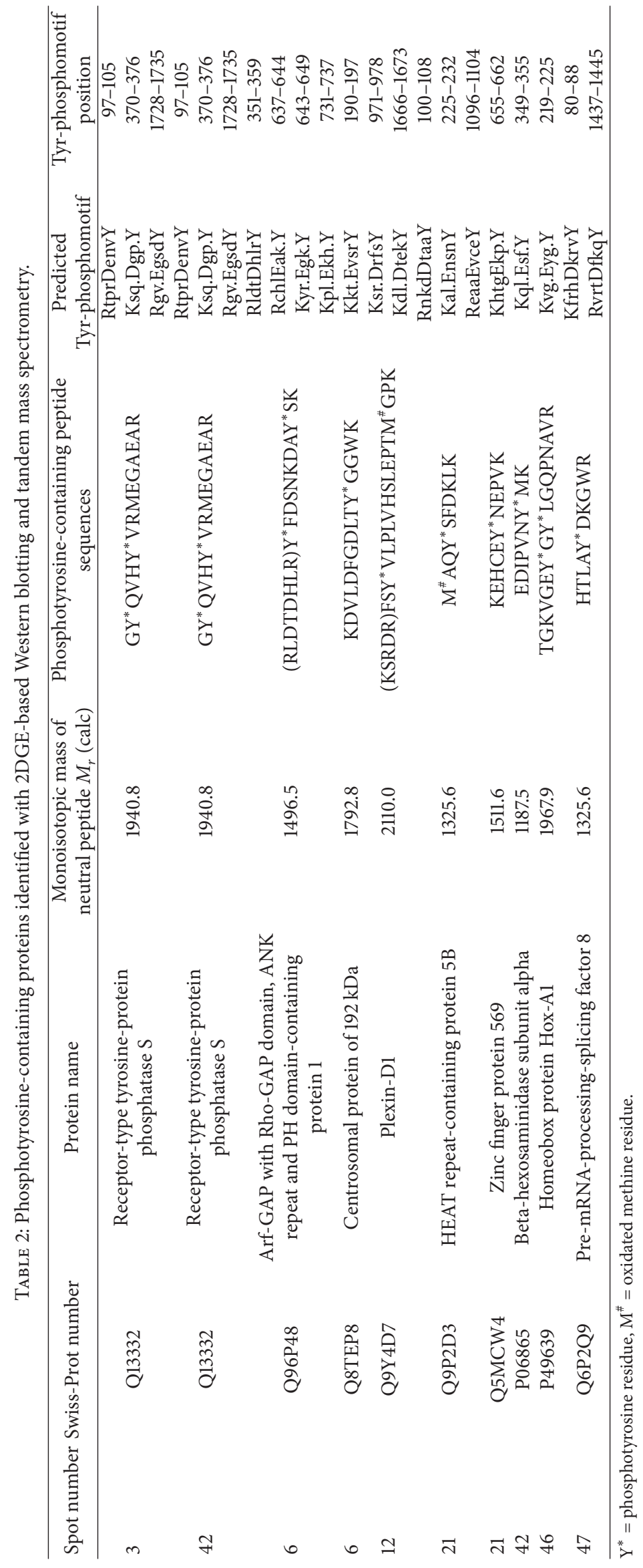


protein of $192 \mathrm{kDa}$, plexin-D1, HEAT repeat-containing protein 5B, zinc finger protein 569, beta-hexosaminidase subunit alpha, homeobox protein Hox-A1, and pre-mRNAprocessing-splicing factor 8 .

\subsection{Protein Domains/Motifs-Based Functional Recognition} of Phosphotyrosine-Containing Proteins. Each protein contained certain structural and functional domains or motifs. Identification of those domains and motifs is helpful to understand the structure and functions of each individual protein. Moreover, tyrosine phosphorylation commonly occurs within a characteristic Tyr-phosphomotif. The identification of Tyr-phosphomotifs further consolidated each identified phosphotyrosine-containing protein. The protein domains and motifs were determined with literature-based bioinformatics and ScanProsite analyses. Each protein contained at least one tyrosine kinase phosphorylation motif (Figures 2 and 3; Tables 1 and 2). It further confirmed the results of $2 \mathrm{D}$-Western blot antiphosphotyrosine immunity reaction. Figures 2 and 3 illustrate all the functional domains of each phosphoprotein.

Figures 2(a) and 2(b) show the functional domains and motifs of heat shock protein 90- (HSP90-) alpha and (HSP90-) beta, which contains 3 Try-phosphomotifs, 5 ATP-binding sites, 1 NLS_BP motif, and 1 TPR repeat-binding. HSP90alpha and HSP90-beta are molecular chaperones promoting the maturation, structural maintenance, and proper regulation of specific target proteins that are involved in cell cycle control and signal transduction and undergo a functional cycle linked to its ATPase activity [53-57]. HSP90-alpha is a homodimer, interacts with STUB1 and UBE2N, and is involved in the ubiquitination systems. HSP90-beta is also a homodimer and interacts with p53/TP53. They are involved in stress response. Mitochondrial HSP75 (Figure 2(c)) contains a Tyr-phosphomotif, 3 ATP binding sites, and two glycosylation motifs; it is a chaperone expressing an ATPase activity and involved in maintaining mitochondrial function and polarization; it interacts with tumor necrosis factor type 1 receptor; and as a negative regulator of mitochondrial respiration, it modulates the balance between oxidative phosphorylation and aerobic glycolysis [58-60]. HSP70 1A/1B (Figure 2(d)) contains 3 nucleotide binding sites and 1 Tyrphosphomotif and is involved in stress-induced damage. Tubulin alpha-1A, tubulin alpha-1B, and tubulin alpha-8 chains (Figures 2(e), 2(f), and 2(g)) contain a nucleotide binding GTP site, ASN_glycosylation, and 1 Tyr-phosphomotif. Tubulin alpha is the major constituent of microtubules and forms dimmer with beta chains, which binds two moles of GTP, one at an exchangeable site on the beta chain and one at a nonexchangeable site on the alpha chain $[61,62]$. Cytoplasmic 1 actin (Figure 2(h)) and beta-actin-like protein 2 (Figure 2(i)) contain the same 2 ACTIN domains, 1 ACTIN ACT LIKE domains, and 2 Tyr-phosphomotifs. Actins are highly conserved proteins that are involved in various types of cell motility and are ubiquitously expressed in all eukaryotic cells. Its phosphorylation would affect cell motility [63]. Glial fibrillary acidic protein (Figure 2(j)) contains 1 Tyrphosphomotif and 3 coil domain, is a class-III intermediate filament, and is a cell-specific marker that distinguishes astrocytes from other glial cells during the development of the central nervous system [64]. L-lactate dehydrogenase B chain (Figure $2(\mathrm{k})$ ) contains 2 Tyr-phosphomotifs, 1 nucleotide binding site, and 1 L-lactate dehydrogenase active site; it is homotetramer in cytoplasm and catalyzes lactate to produce pyruvate and NADH [65]. 14-3-3 protein epsilon (Figure 2(1)) contains two 14-3-3 domains, two recognitions of phosphoserine motifs, and one Tyr-phosphomotif; it is homodimer in cytoplasm and participates in the regulation of a wide-range of signaling pathways [66]. Annexin A5 (Figure 2(m)) contains 1 Tyr-phosphomotif and 4 ANNEXIN domains that bind calcium and phospholipid acts, and it acts as an indirect inhibitor of the thromboplastin-specific complex [67]. Apolipoprotein A-I (Figure 2(n)) contains 10 approximate tandem repeats and 1 Tyr-phosphomotif. It is a secreted protein and is involved in the reverse transport of cholesterol from tissues to the liver for excretion by promoting cholesterol efflux from tissues and by acting as a cofactor for the lecithin cholesterol acyltransferase and participates in lipid metabolism [68]. Alpha-enolase (Figure 2(o)) contains 2 Tyr-phosphomotifs and 1 enolase signature and 1 substrate binding region. Alpha-enolase is a multifunctional enzyme that is involved in various processes such as growth control, hypoxia tolerance, and allergic responses, also functions in the intravascular and pericellular fibrinolytic system [69], and has been used as diagnostic marker for many tumors [70].

Figure 3(a) shows the protein domains and motifs of receptor-type tyrosine-protein phosphatase S, including 3 Iglike C2-type domains, 1 fibronectin type-III domain, 1 transmembrane region, 2 tyrosine-protein phosphatases, and 3 Tyr-phosphomotifs; it is involved in receptor desensitization, signal transduction, and membrane localization [71]. ArfGAP with Rho-GAP domain, ANK repeat, and PH domaincontaining protein 1 (Figure $3(\mathrm{~b})$ ) contains $4 \mathrm{PH}$ domains, 1 Ras-associating domain, 1 Rho-GAP domain, 1 Arf-GAP domain, and 4 Tyr-phosphomotifs; it is a phosphatidylinositol 3,4,5-trisphosphate-dependent GTPase-activating protein that modulates actin cytoskeleton remodeling by regulating ARF and RHO family members [72]. Centrosomal protein of $192 \mathrm{kDa}$ (Figure 3(c)) contains 3 phosphoserine sites and 1 Tyr-phosphomotif; its hydroxylation promotes ubiquitination [73]. Plexin-D1 (Figure 3(d)) is a transmembrane protein, containing 1 SEMA domain, 3 IPT/TIG domains, and 2 Tyr-phosphomotifs; it plays an important role in cellcell signaling and in regulating the migration of a wide spectrum of cell types [74]. HEAT repeat-containing protein 5B (Figure 3(e)) contains 3 HEAT domains and 3 Tyrphosphomotifs and is involved in the regulation of cell cycle [75]. Zinc finger protein 569 (Figure 3(f)) contains 19 zinc finger $\mathrm{C}_{2} \mathrm{H}_{2}$ type domains, 1 KRAB domain, and 1 Tyrphosphomotif; it involved transcription regulation and suppresses MAPK signaling pathway [76]. Beta-hexosaminidase subunit alpha (Figure $3(\mathrm{~g})$ ) contains a critical motif for hydrolysis GM2 gangliosides and a propeptide and 1 Tyrphosphomotif; it is responsible for the degradation of GM2 gangliosides and a variety of other molecules containing terminal $\mathrm{N}$-acetyl hexosamines, in the brain and other tissues [77]. Homeobox protein Hox-A1 (Figure 3(h)) contains 2 Poly-HIS, 1 homeobox 2, 1 poly-Ser, Antp-type 


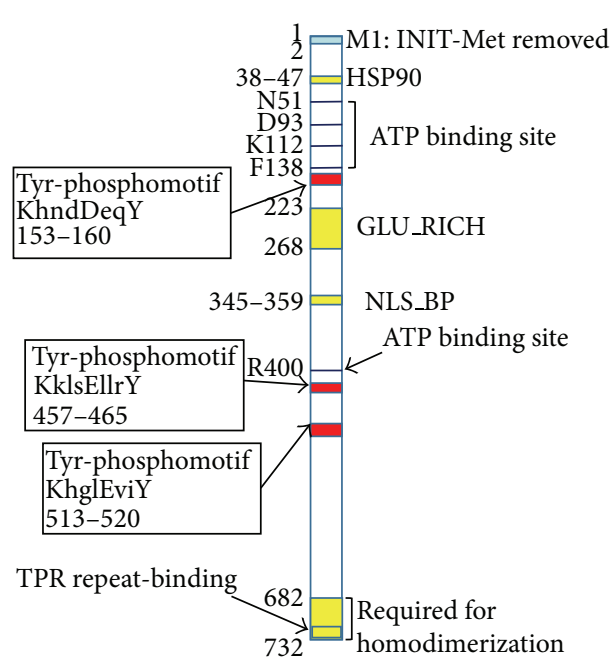

Heat shock protein HSP 90-alpha

(a)

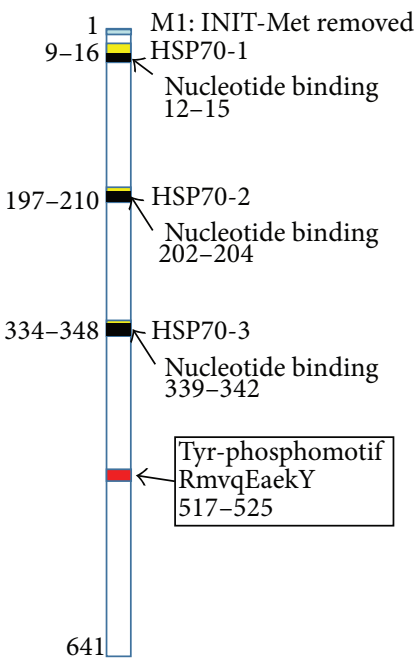

Heat shock $70 \mathrm{kDa}$ protein $1 \mathrm{~A} / 1 \mathrm{~B}$

(d)

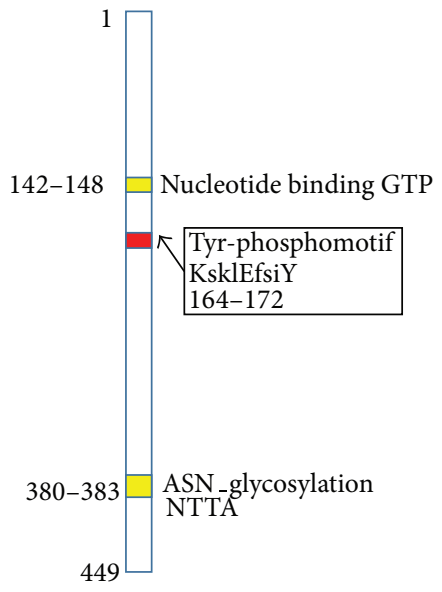

Tubulin alpha-8 chain

(g)

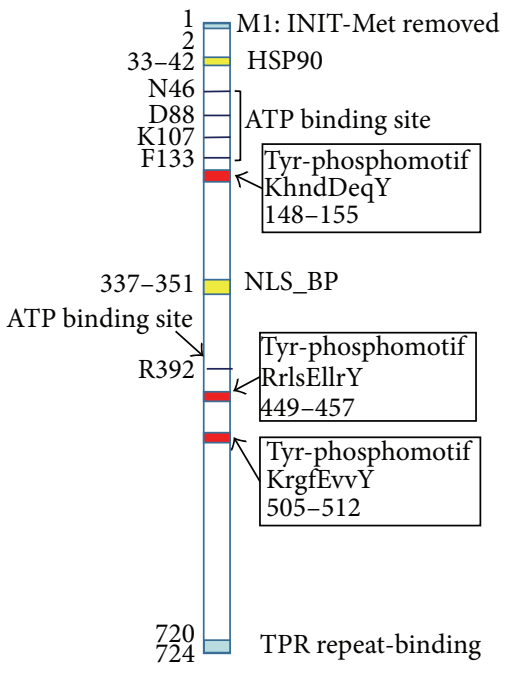

Heat shock protein HSP 90-beta

(b)

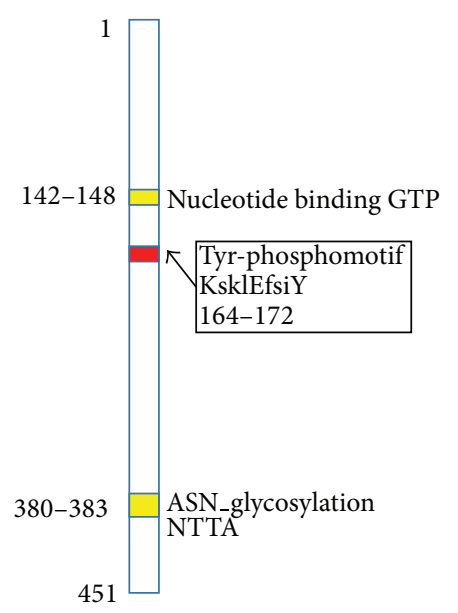

Tubulin alpha-1A chain

(e)

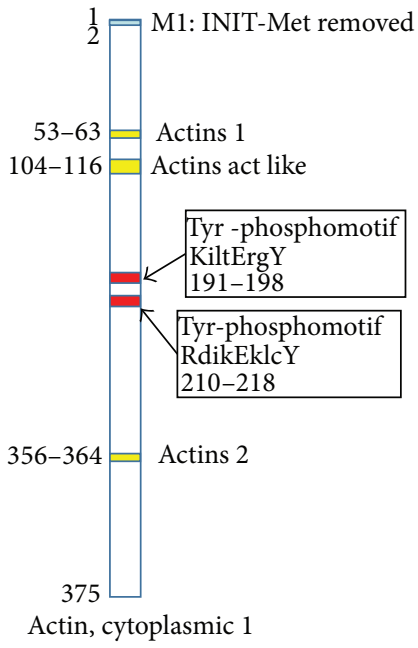

(h)

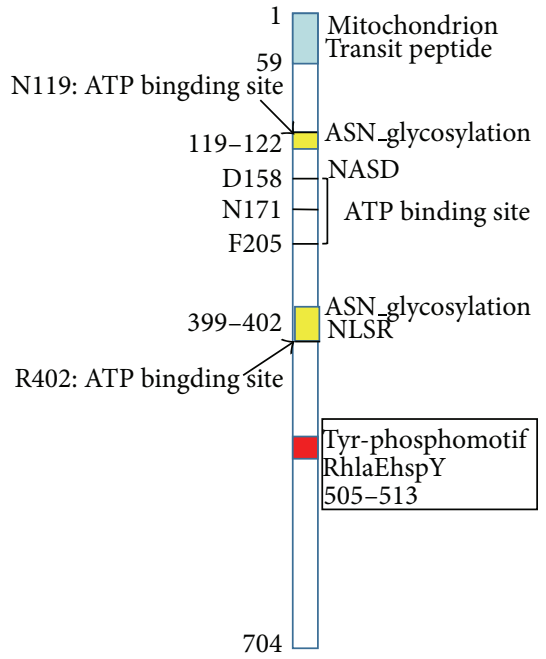

Heat shock protein $75 \mathrm{kDa}$, mitochondrial

(c)

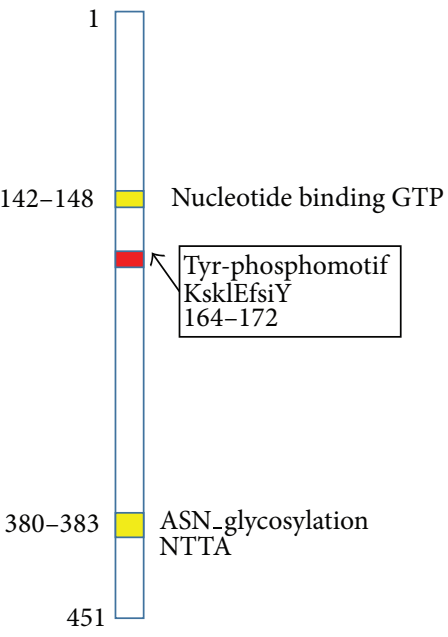

Tubulin alpha-1B chain

(f)

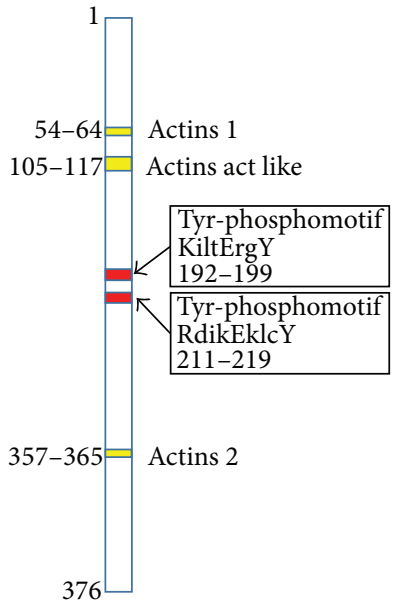

Beta-actin-like protein 2

FIGURe 2: Continued. 


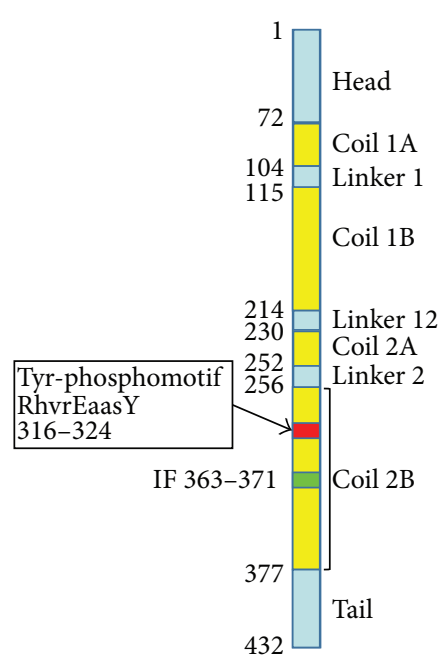

Glial fibrillary acidic protein

(j)

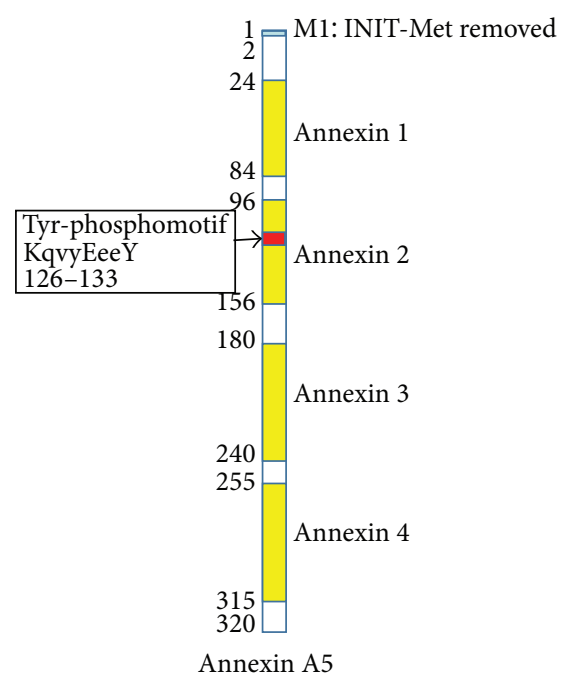

$(\mathrm{m})$

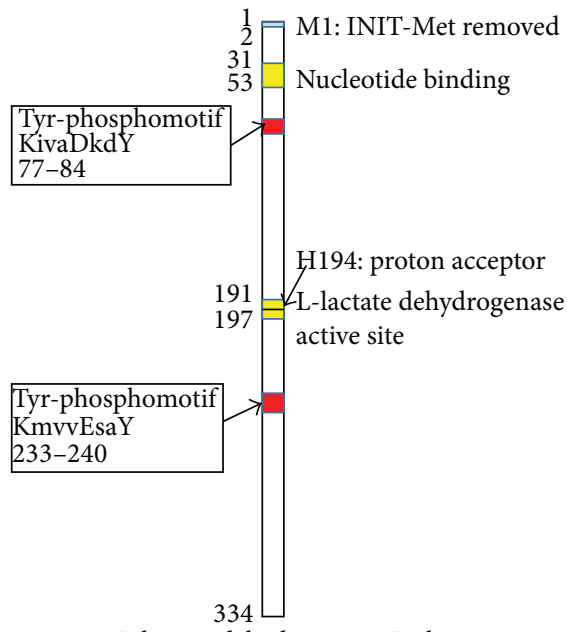

L-lactate dehydrogenase B chain

(k)

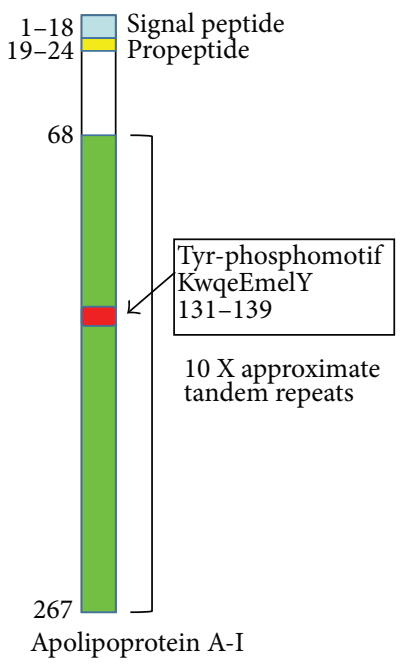

(n)

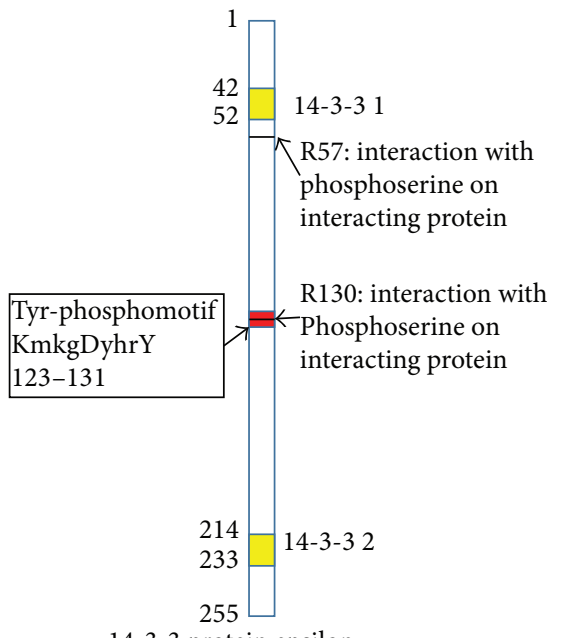

(l)

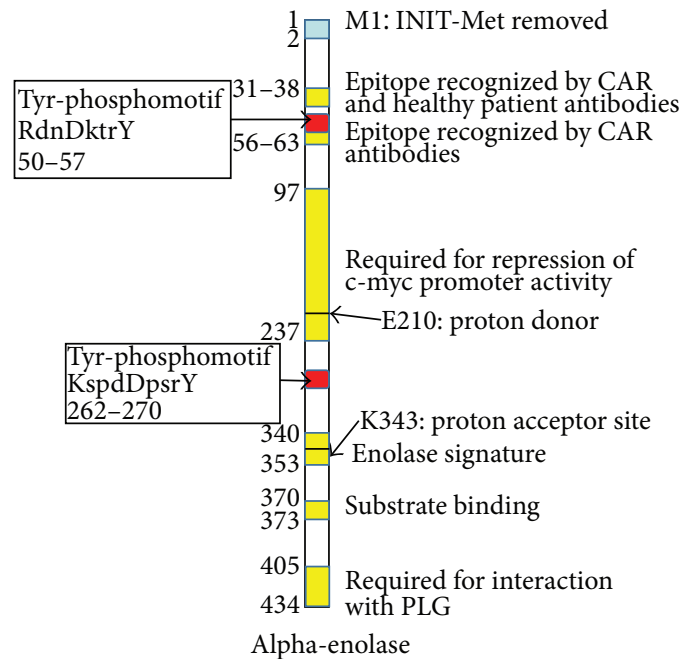

(o)

FIGURE 2: Tyrosine kinase phosphorylation motif and functional domains of putative phosphotyrosine-containing proteins in a glioblastoma tissue. INIT-Met, initiator methionine; HSP90, heat shock protein 90 family signature; GLU_RICH, glutamic acid-rich region profile; NLS_BP, bipartite nuclear localization signal profile; TPR, tetratricopeptide; ASN, N-glycosylation site; HSP70, heat shock protein 70 family signature; GTP, guanosine triphosphate; PLG, plasminogen.

hexapeptide, and 1 Tyr-phosphomotif; it is involved in transcription regulations [78]. Pre-mRNA-processing-splicing factor 8 (Figure 3(i)) contains a reverse transcriptase homology domain, a restriction endonuclease homology domain, an RNase $\mathrm{H}$ homology domain, an MPN, and 2 Tyrphosphomotifs; it is involved in mRNA processing and functions as a scaffold that mediates the ordered assembly of spliceosomal proteins and snRNAs [79].

3.4. Systems Biology Strategy-Based Recognition of Biological Functions of Phosphotyrosine-Containing Proteins. Functional enrichment analysis was performed for 24 phosphotyrosine-containing proteins identified from a glioblastoma tissue; their biological functions were rationalized in glioblastoma. All the 24 phosphotyrosine-containing proteins were accepted for GO analysis and CytoScape BINGO analysis and were hierarchically classified into 4 clusters (Table 3). Proteins within the same cluster were coregulated proteins and might have similar biological functions in the glioblastoma. Those phosphoproteins were involved in multiple biological functions altered in glioblastoma, including oxidative stress and stress response and cell migration. Significantly, GO analysis showed that different biological functions changed during the pathophysiological processes of glioblastoma.

Pathway network analysis further revealed the potential biological functions of those characterized phosphotyrosinecontaining proteins in a human glioblastoma. Among 24 phosphotyrosine-containing proteins (Supplemental Table 2 ), all those 24 phosphotyrosine-containing proteins were accepted for IPA analysis to determine significant pathway networks, canonical pathways, and disease biological events. 


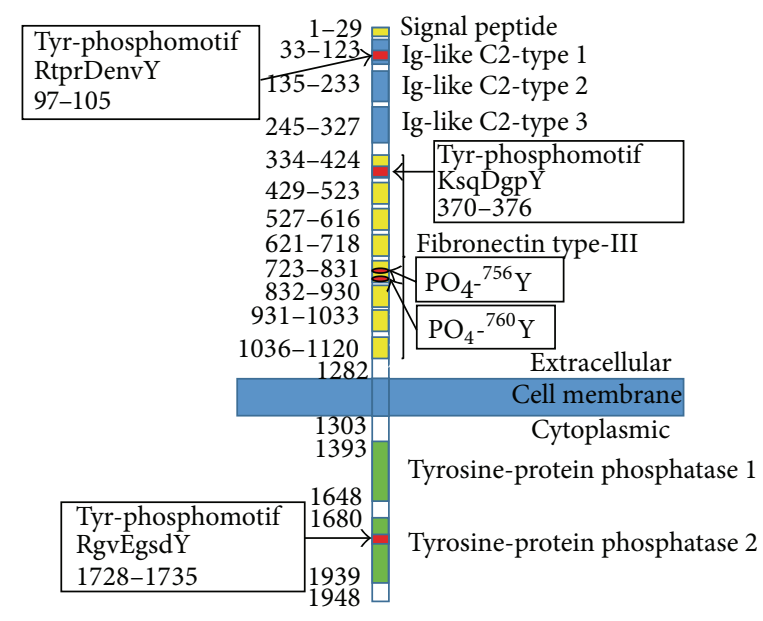

Receptor-type tyrosine-protein phosphatase S

(a)

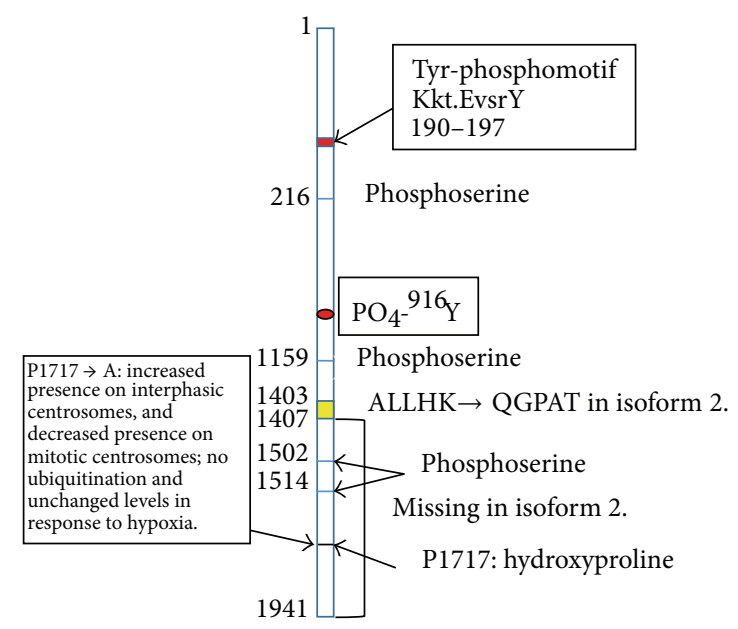

Centrosomal protein of $192 \mathrm{kDa}$

(c)

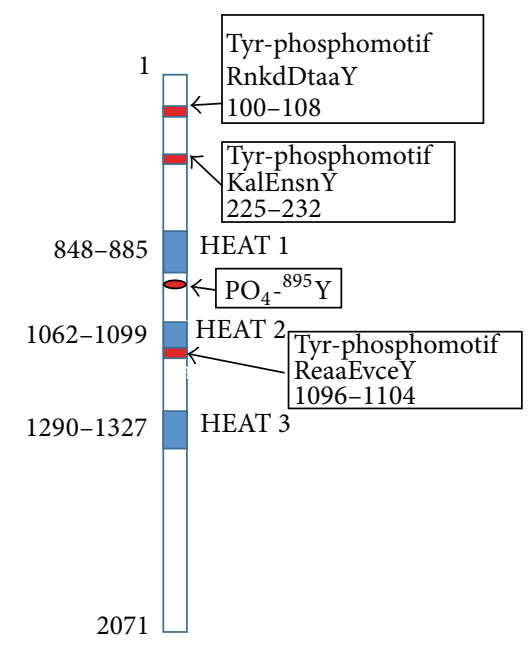

HEAT repeat-containing protein $5 \mathrm{~B}$

(e)

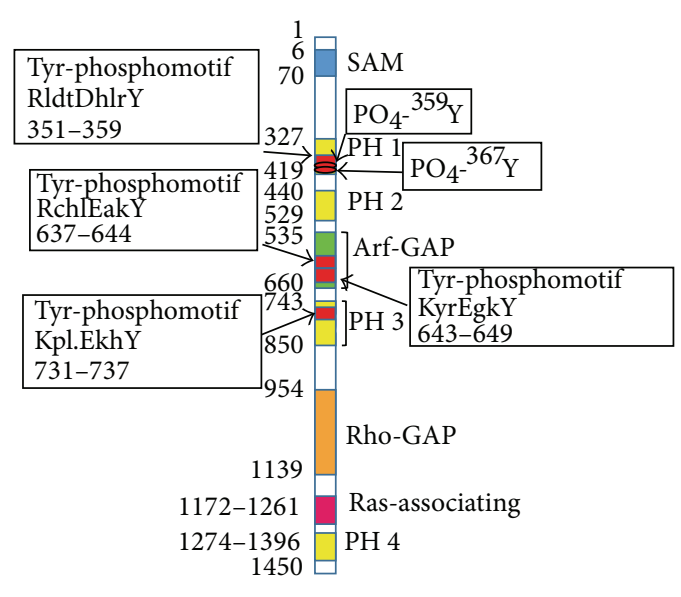

Arf-GAP with Rho-GAP domain, ANK repeat and $\mathrm{PH}$ domain-containing protein 1

(b)

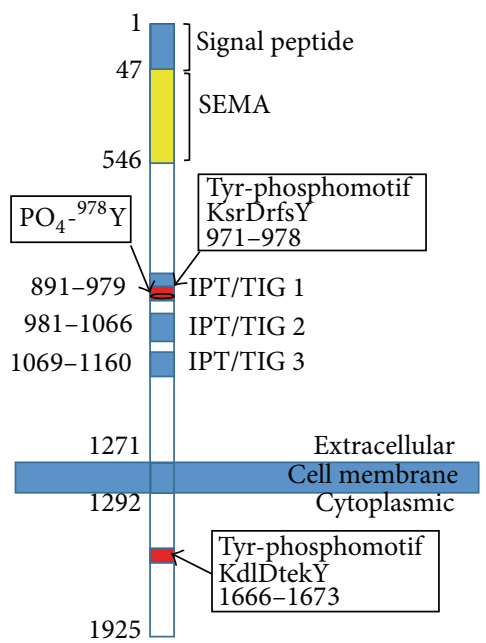

Plexin-D1

(d)

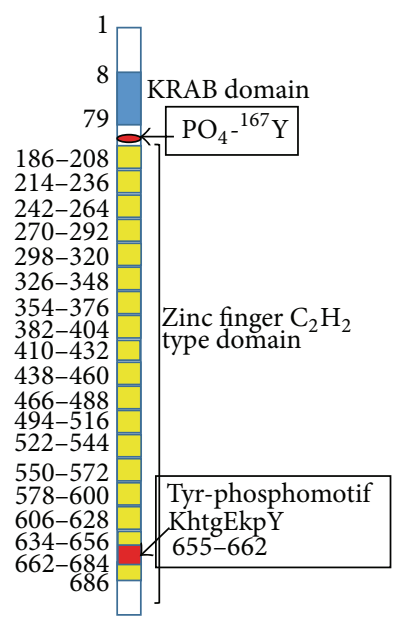

Zinc finger protein 569

(f)

Figure 3: Continued. 


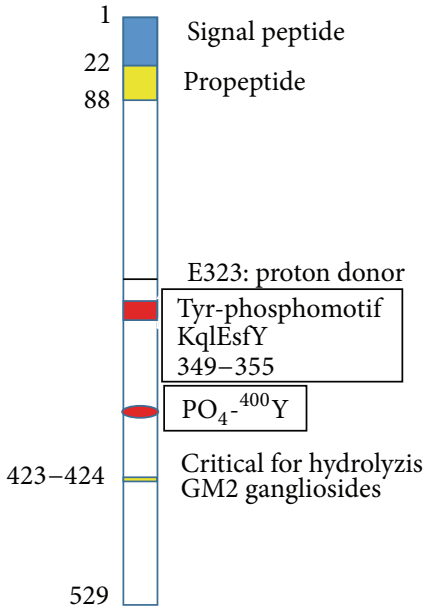

Beta-hexosaminidase subunit alpha

(g)

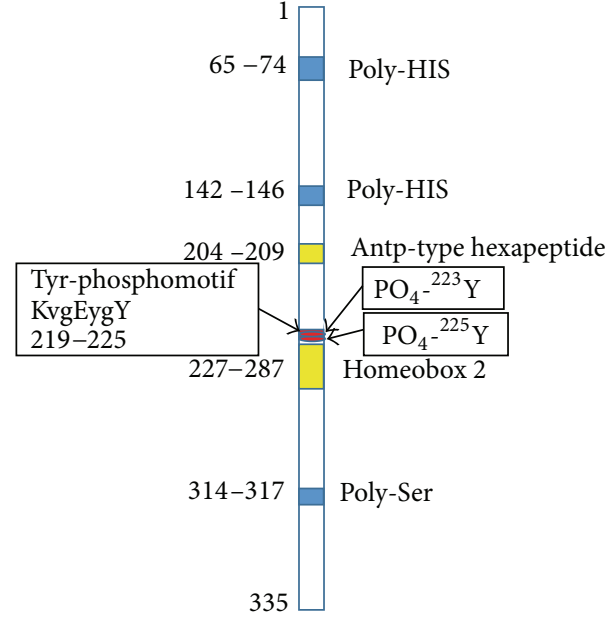

Homeobox protein Hox-A1

(h)

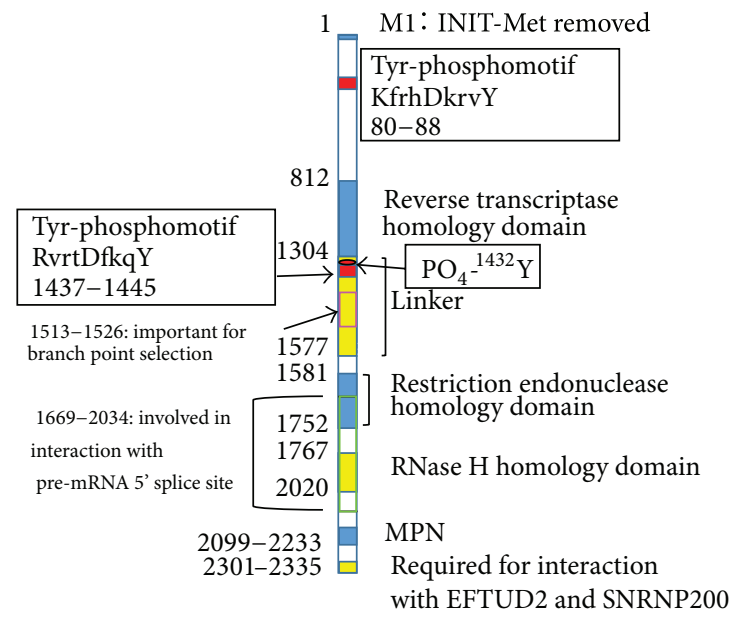

Pre-mRNA-processing-splicing factor 8

(i)

Figure 3: Phosphotyrosine sites, tyrosine kinase phosphorylation motifs, and functional domains of phosphotyrosine-containing proteins in a glioblastoma tissue. SAM, the sterile $\alpha$ motif; PH, pleckstrin homology; Arf-GAP, ADP ribosylation factor GTPase-activating protein domain; Rho-GAP, Rho GTPase-activating proteins domain; SEMA, semaphorins; IPT/TIG, Ig-like, plexins, transcription factors/trigger factor-like protein; KRAB, Krueppel-associated box; GM2, the second monosialic ganglioside; HIS, histidine; MPN, domain at Mprlp and Padlp N-termini; EFTUD2, elongation factor Tu GTP-binding domain-containing protein 2; SNRNP200, small nuclear ribonucleoprotein $200 \mathrm{kDa}$.

Two statistically significant pathway networks were identified to involve the phosphotyrosine-containing proteins (Figure 4 and Supplemental Table 3). Those nodes in Figure 4 correspond to those molecules (genes; proteins) that were summarized in Supplemental Table 3. Network A (Figure 4(a)) functions in cancer, organismal injury and abnormalities, reproductive system disease, and developmental disorder (merged from Networks 1 and 3 in the Supplemental Table 3 ) and includes 39 nodes (genes; proteins). Among those 39 nodes, 17 phosphotyrosine-containing proteins (44\% of the total nodes) were identified with MS. ERK, Akt, P38MAPK, Jnk, HSP90, HSP70, tubulin complex, NF- $\kappa$ B complex, and insulin play key roles in this network. Network B (Figure 4(b)) functions in cell morphology, cellular assembly and organization, cellular function, and maintenance (corresponded to Network 2 in the Supplemental Table 3) and includes 35 nodes (genes; proteins). Among those 35 nodes, 7 phosphotyrosine-containing proteins $(20 \%$ of the total nodes) were identified with MS. TNF, UBC, and CEP192 play key roles in this network.

Among those sets of glioblastoma phosphotyrosinecontaining protein data, 36 statistically significant canonical pathways were identified to involve those phosphotyrosinecontaining proteins (Figure 5). Each detailed statistically 


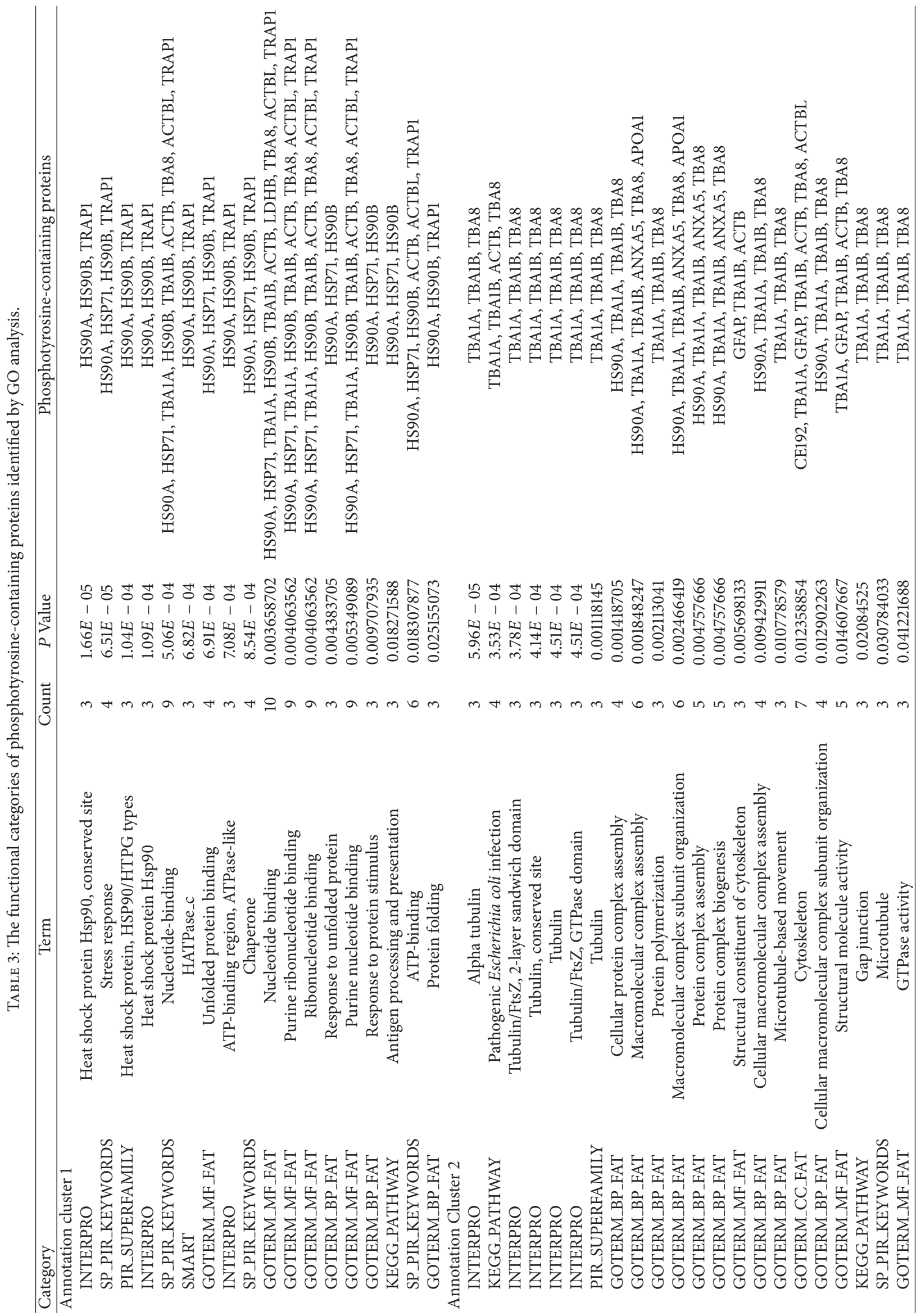




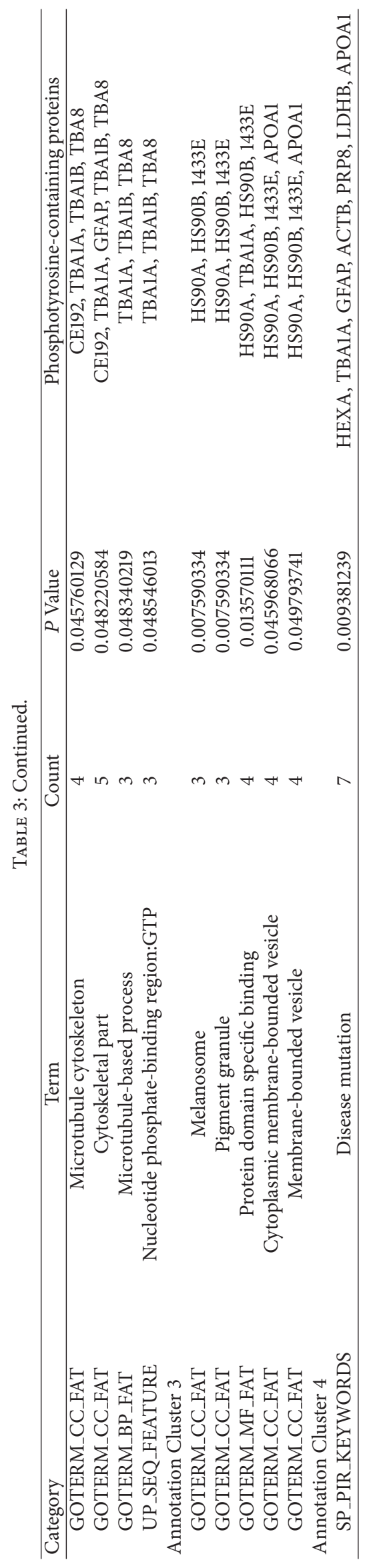



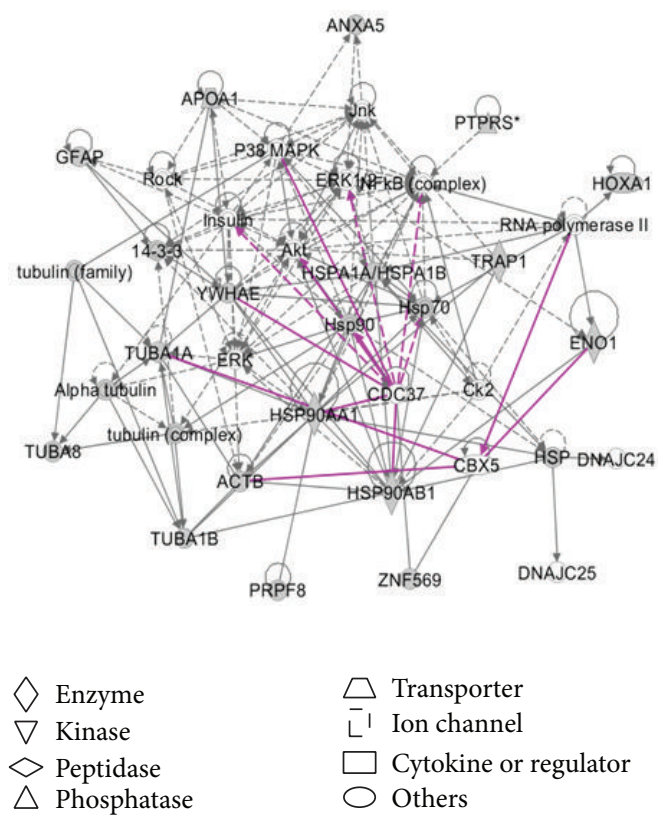

(a)
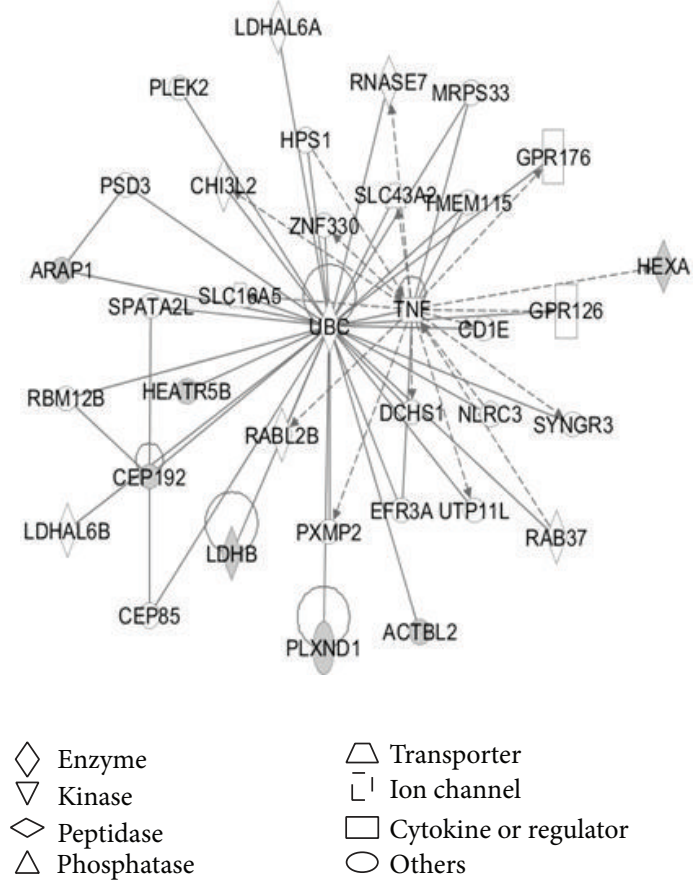

$\triangle$ Phosphatase

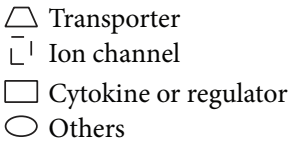

(b)

FIGURE 4: Significant signaling pathway networks mined from phosphotyrosine-containing proteins in a glioblastoma tissue. Significant signaling pathway networks that are involved in human glioblastoma phosphotyrosine-containing proteins and that function in (a) cancer, organismal injury and abnormalities, reproductive system disease, and developmental disorder (merged Networks 1 and 3 in the Supplemental Table 3) and (b) cell morphology, cellular assembly and organization, cellular function, and maintenance (Network 2). A black solid edge denotes a direct relationship between two nodes (molecules: proteins; genes). A black unsolid edge denotes an indirect relationship between two nodes (molecules: proteins; genes). The various shapes of nodes denote the different functions. A curved line means intracellular translocation; a curved arrow means extracellular translocation.

significant canonical pathway was collected in Supplemental Figure 1, including 14-3-3-mediated signaling, cell cycle G2/M DNA damage checkpoint regulation, eNOS signaling, gap junction signaling, gluconeogenesis I, glycolysis I, HIFla signaling, PI3K-AKT signaling, protein ubiquitination pathway, pyruvate fermentation to lactate, signaling by Rho family GTPases, and VEGF signaling. Moreover, 74 statistically significant disease biological events (Figure 6) involved those phosphotyrosine-containing proteins, including cancer, endocrine system disorders, neurological disease, inflammatory disease, cell cycle dysregulation, energy metabolism, immunity, and protein synthesis. Those pathway networks, canonical pathways, and disease biological events provided a functional profile of those phosphotyrosine-containing proteins in human glioblastoma.

Furthermore, extensive literature-based analysis proposed an experimental data-based diagram that rationalizes the identified phosphotyrosine-containing proteins in the glioma biological system (Figure 7). Those phosphotyrosinecontaining proteins are involved in tumor cell proliferation, growth, adhesion, migration, angiogenesis, tumor metastasis, blood supply, nutrition, signal transduction, and oxidative stress to associate the processes of tumor pathogenesis.

\section{Conclusions}

The present study provides new insights to explore the presence and biological significance of tyrosine phosphorylation in the pathological processes of glioblastoma. The combination of Western blotting and LC-ESI-MS/MS is an effective method to detect and characterize phosphotyrosinecontaining proteins in human glioblastoma proteome. 2DGE-based Western blotting can preseparate and enrich proteins with a similar $\mathrm{pI}$ and $M_{r}$. LC can real-time preseparate and enrich those tryptic peptides before mass spectrometry analysis. MS/MS can accurately locate each phosphotyrosine site. Protein domain/motif analysis can locate the phosphotyrosine site within the corresponding protein domains. Each identified phosphotyrosine-containing protein contains at least one Tyr-phosphomotif. Pathway analysis-based bioinformatics can reveal the signaling pathway networks that involve phosphoproteins. This methodology provides a basis to comprehensively investigate the phosphotyrosine-containing proteome in the human glioblastoma, especially to achieve our goal to detect and characterize glioma-related phosphotyrosine-containing proteins in a program to clarify the basic molecular mechanisms of glioblastoma formation. Further investigation is needed to determine the biological consequences of the identified 


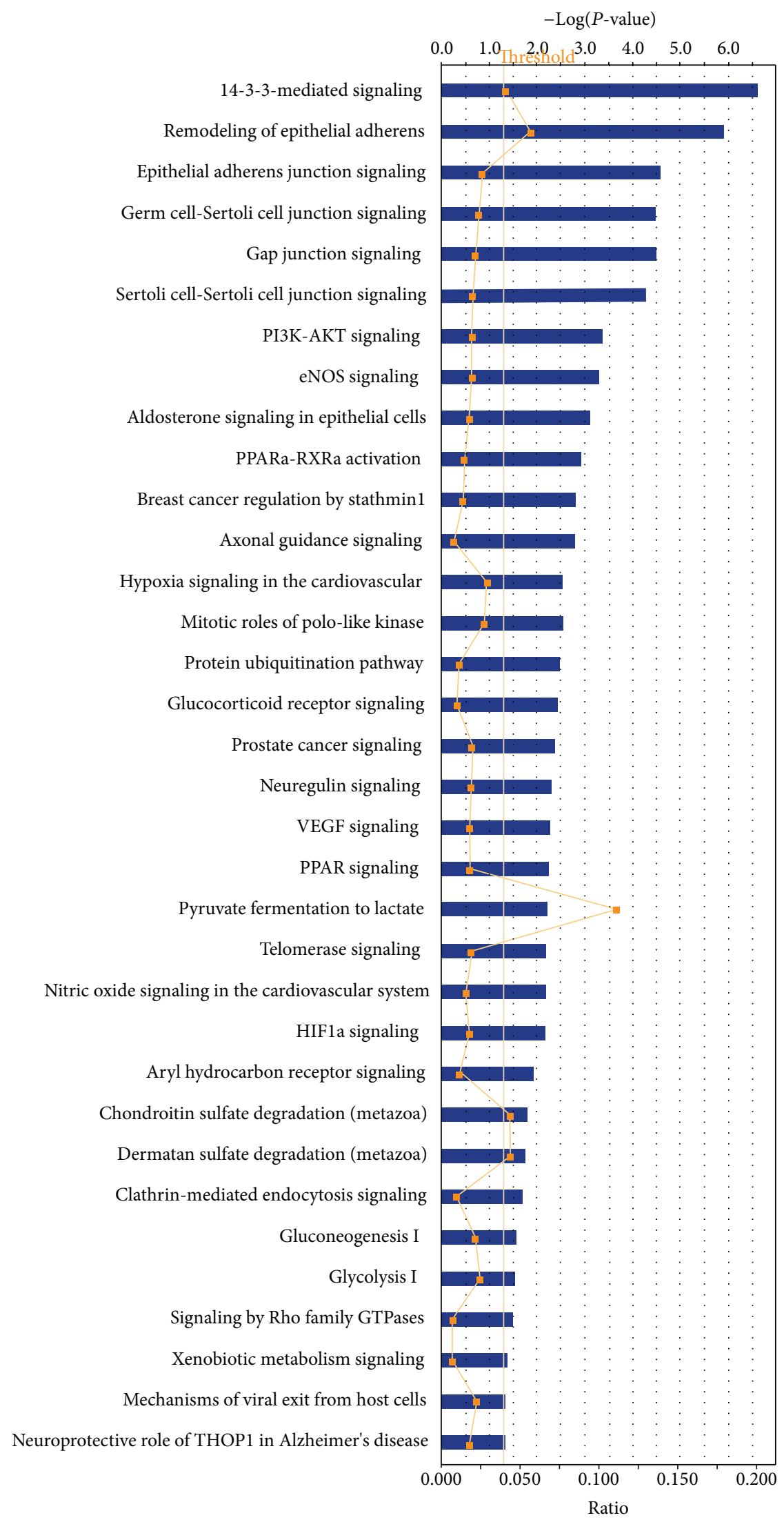

FIGURE 5: Significant canonical pathways that are involved with phosphotyrosine-containing proteins in a glioblastoma tissue. Each significant canonical pathway was collected as in Supplemental Figure 1. 


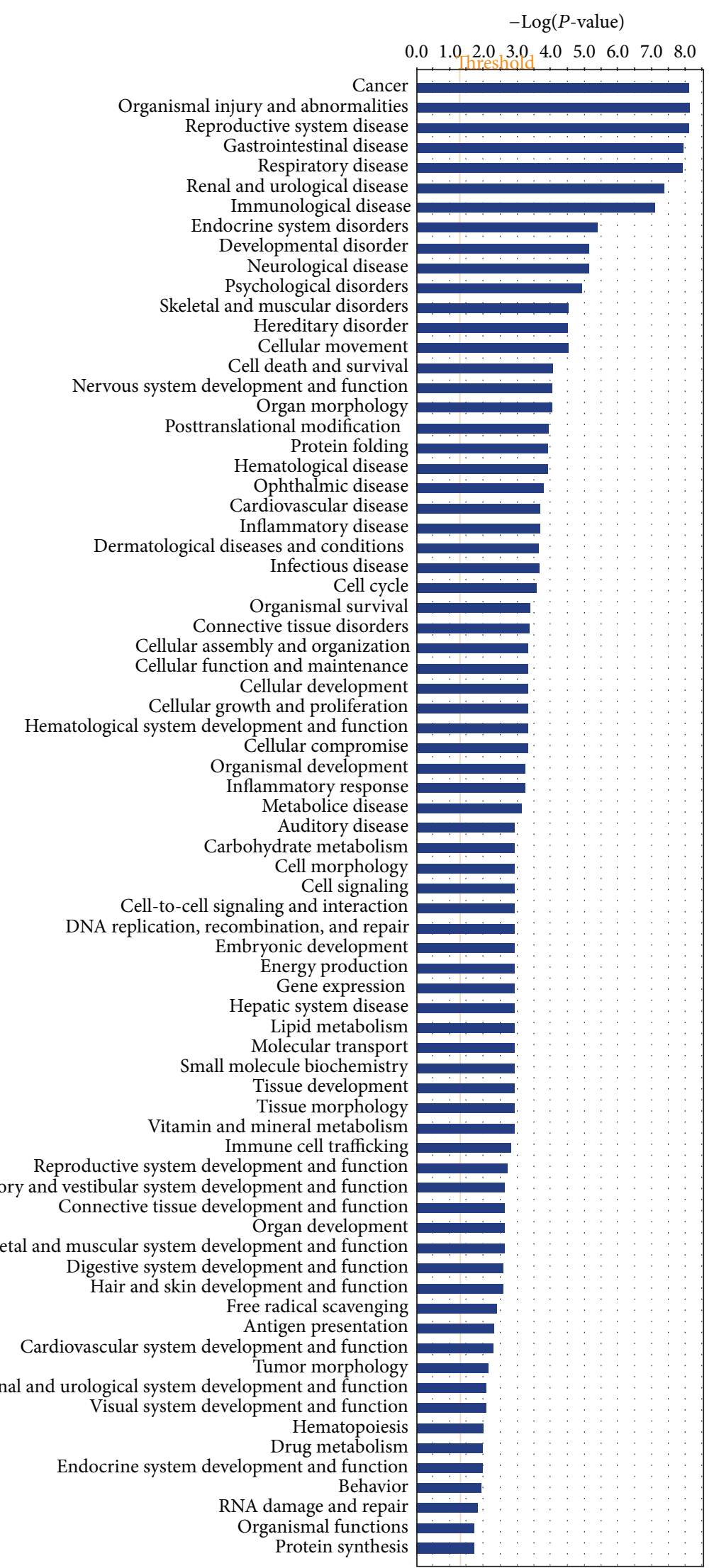

FIGURE 6: Significant disease biological events that are involved with phosphotyrosine-containing proteins in a glioblastoma tissue. 


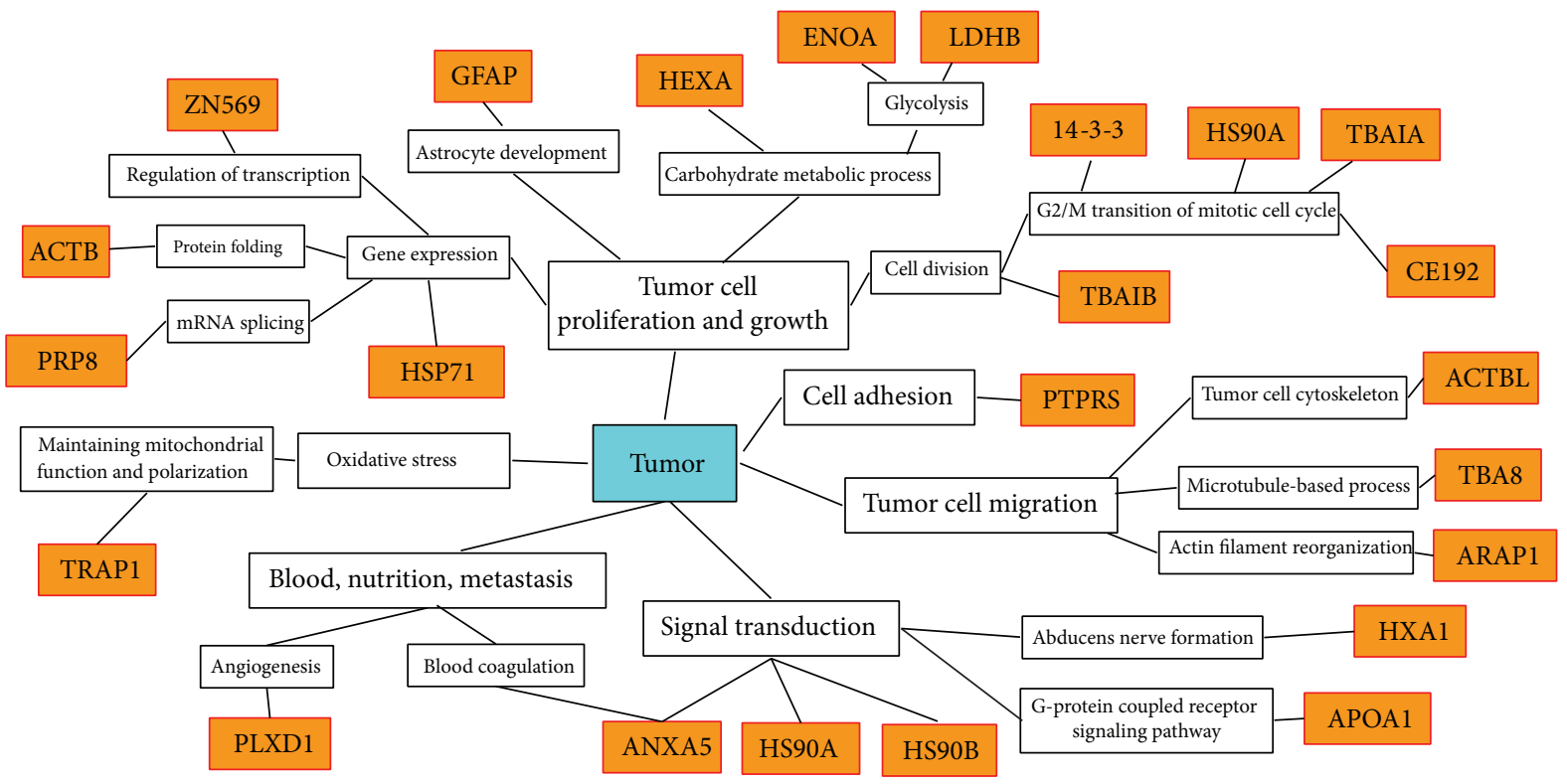

FIGURE 7: Experimental data-based diagram that rationalizes phosphotyrosine-containing proteins in the glioma biological system. The orange frame means identified phosphotyrosine-containing proteins. ANXA5, annexin A5; PLXD1, plexin-D1; TRAP1, TNFR-associated protein 1 (heat shock protein $75 \mathrm{kDa}$, mitochondrial); PRP8, pre-mRNA-processing-splicing factor 8; ACTB, actin, cytoplasmic 1; ZN569, zinc finger protein 569; GFAP, glial fibrillary acidic protein; HEXA, beta-hexosaminidase subunit alpha; ENOA, alpha-enolase; LDHB, Llactate dehydrogenase B chain; 14-3-3, 14-3-3 protein; HSP90A, heat shock protein HSP 90-alpha; TBAIA, tubulin alpha-1A chain; CE192, centrosomal protein of $192 \mathrm{kDa}$; ACTBL, beta-actin-like protein 2; TBA8, tubulin alpha-8 chain; ARAP1, Arf-GAP with Rho-GAP domain, ANK repeat, and PH domain-containing protein 1; HXA1, homeobox protein Hox-A1; APOA1, apolipoprotein A-I; and HSP90B, heat shock protein HSP 90-beta.

tyrosine phosphorylation events and their relevance to the pathogenic mechanisms of glioblastoma.

\section{Abbreviations}

BSA: Bovine serum albumin

CHAPS: 3-(3-Cholamidopropyl)dimethylammonio-1propanesulfonate

DTT: Dithiothreitol

EGF: Epidermal growth factor

EGFR: Epidermal growth factor receptor

FRK: $\quad$ Fyn related kinase

ESI: Electrospray ionization

GO: Geneontology

HSP: Heat shock protein

IEF: Isoelectric focusing

IPA: Ingenuity pathway analysis

IPG: Immobilized $\mathrm{pH}$ gradient

LC: liquid chromatography

LRRC4: Leucine-rich repeat C4

MS: $\quad$ Mass spectrometry

MS/MS: Tandem mass spectrometry

OD: Optical density

PDGF: Platelet-derived growth factor

PDGFR: Platelet-derived growth factor receptor

PTK: $\quad$ Protein tyrosine kinase

PTP: $\quad$ Protein tyrosine phosphatase

PVDF: Polyvinylidene fluoride

qTOF: Quadrupole time of flight
RTK: $\quad$ Receptor tyrosine kinase

SDS: $\quad$ Sodium dodecyl sulfonate

SDS-PAGE: Sodium dodecyl sulfate-polyacrylamide gel electrophoresis

2D: Two-dimensional

2DGE: Two-dimensional gel electrophoresis

TBS: $\quad$ Tris-buffered saline

TEMED: Tetramethylethylenediamine

VEGF: Vascular endothelial growth factor

VEGFR: Vascular endothelial growth factor receptor.

\section{Conflict of Interests}

The authors declare that there is no conflict of interests regarding the publication of this article.

\section{Acknowledgments}

The authors acknowledge the financial supports from the National Natural Science Foundation of China (Grant no. 81272798 to Xianquan Zhan), the Xiangya Hospital Funds for Talent Introduction (to Xianquan Zhan), the Hunan Provincial Natural Science Foundation of China (Grant no. 14JJ7008 to Xianquan Zhan), China "863" Plan Project (Grant no. 2014AA020610-1 to Xianquan Zhan), ingenuity from the Ingenuity Pathway Analysis free-trial program, and the constructed canonical pathways. 


\section{References}

[1] X. Zhang, K. Højlund, M. Luo, C. Meyer, T. Geetha, and Z. Yi, "Novel tyrosine phosphorylation sites in rat skeletal muscle revealed by phosphopeptide enrichment and HPLCESI-MS/MS," Journal of Proteomics, vol. 75, no. 13, pp. 40174026, 2012.

[2] H. Zheng, P. Hu, D. F. Quinn, and Y. K. Wang, "Phosphotyrosine proteomic study of interferon $\alpha$ signaling pathway using a combination of immunoprecipitation and immobilized metal affinity chromatography," Molecular and Cellular Proteomics, vol. 4, no. 6, pp. 721-730, 2005.

[3] T. Tunter, "Tyrosine phosphorylation: thirty years and counting," Current Opinion in Cell Biology, vol. 21, no. 2, pp. 40-46, 2009.

[4] S. Lamprianou and S. Harroch, "Receptor protein tyrosine phosphatase from stem cells to mature glial cells of the central nervous system," Journal of Molecular Neuroscience, vol. 29, no. 3, pp. 241-255, 2006.

[5] T. Hunter, "Synthetic peptide substrates for a tyrosine protein kinase," The Journal of Biological Chemistry, vol. 257, no. 9, pp. 4843-4848, 1982.

[6] J. A. Cooper, F. S. Esch, S. S. Taylor, and T. Hunter, "Phosphorylation sites in enolase and lactate dehydrogenase utilized by tyrosine protein kinase in vivo and in vitro," The Journal of Biological Chemistry, vol. 259, no. 12, pp. 7835-7841, 1984.

[7] T. Patschinsky, T. Hunter, F. S. Esch, J. A. Cooper, and B. M. Sefton, "Analysis of the sequence of amino acids surrounding sites of tyrosine phosphorylation," Proceedings of the National Academy of Sciences of the United States of America, vol. 79, no. 4, pp. 973-977, 1982.

[8] G. Manning, D. B. Whyte, R. Martinez, T. Hunter, and S. Sudarsanam, "The protein kinase complement of the human genome," Science, vol. 298, no. 5600, pp. 1912-1934, 2002.

[9] P. Blume-Jensen and T. Hunter, "Oncogenic kinase signalling," Nature, vol. 411, no. 6835, pp. 355-365, 2001.

[10] H. Johnson and F. M. White, "Toward quantitative phosphotyrosine profiling in vivo," Seminars in Cell \& Developmental Biology, vol. 23, no. 8, pp. 854-862, 2012.

[11] A. D. Zoumaro-Djayoon, A. J. R. Heck, and J. Muñoz, "Targeted analysis of tyrosine phosphorylation by immuno-affinity enrichment of tyrosine phosphorylated peptides prior to mass spectrometric analysis," Methods, vol. 56, no. 2, pp. 268-274, 2012.

[12] P. A. Futreal, A. Kasprzyk, E. Birney, J. C. Mullikin, R. Wooster, and M. R. Stratton, "Cancer and genomics," Nature, vol. 409, no. 6822, pp. 850-852, 2001.

[13] T. Hunter and B. M. Sefton, "Transforming gene product of Rous sarcoma virus phosphorylates tyrosine," Proceedings of the National Academy of Sciences of the United States of America, vol. 77, no. 3, pp. 1311-1315, 1980.

[14] I. Amit, R. Wides, and Y. Yarden, "Evolvable signaling networks of receptor tyrosine kinases: relevance of robustness to malignancy and to cancer therapy," Molecular Systems Biology, vol. 3, article 151, 2007.

[15] U. Andersson, D. Johansson, P. Behnam-Motlagh, M. Johansson, and B. Malmer, "Treatment schedule is of importance when gefitinib is combined with irradiation of glioma and endothelial cells in vitro," Acta Oncologica, vol. 46, no. 7, pp. 951-960, 2007.

[16] P. Traxler, P. R. Allegrini, R. Brandt et al., "AEE788: a dual family epidermal growth factor receptor/ErbB2 and vascular endothelial growth factor receptor tyrosine kinase inhibitor with antitumor and antiangiogenic activity," Cancer Research, vol. 64, no. 14, pp. 4931-4941, 2004.

[17] A. C. Navis, A. Bourgonje, P. Wesseling et al., "Effects of dual targeting of tumor cells and stroma in human glioblastoma xenografts with a tyrosine kinase inhibitor against c-MET and VEGFR2," PLoS ONE, vol. 8, no. 3, Article ID e58262, 2013.

[18] M. Wu, C. Huang, X. Li et al., "LRRC4 inhibits glioblastoma cell proliferation, migration, and angiogenesis by downregulating pleiotropic cytokine expression and responses," Journal of Cellular Physiology, vol. 214, no. 1, pp. 65-74, 2008.

[19] H. K. Gan, M. Lappas, D. X. Cao, A. Cvrljevdic, A. M. Scott, and T. G. Johns, "Targeting a unique EGFR epitope with monoclonal antibody 806 activates NF- $\kappa \mathrm{B}$ and initiates tumour vascular normalization," Journal of Cellular and Molecular Medicine, vol. 13, no. 9, pp. 3993-4001, 2009.

[20] F. Ye, Q. Gao, T. Xu et al., "Upregulation of LRIG1 suppresses malignant glioma cell growth by attenuating EGFR activity," Journal of Neuro-Oncology, vol. 94, no. 2, pp. 183-194, 2009.

[21] A. H. Sikkema, E. S. J. M. de Bont, G. Molema et al., "Vascular endothelial growth factor receptor 2 (VEGFR-2) signalling activity in paediatric pilocytic astrocytoma is restricted to tumour endothelial cells," Neuropathology and Applied Neurobiology, vol. 37, no. 5, pp. 538-548, 2011.

[22] I. Sancho-Martinez and A. Martin-Villalba, "Tyrosine phosphorylation and CD95: a FAScinating switch," Cell Cycle, vol. 8, no. 6, pp. 838-842, 2009.

[23] B. C. Merk, J. L. Owens, M.-B. S. Lopes, C. M. Silva, and I. M. Hussaini, "STAT6 expression in glioblastoma promotes invasive growth," BMC Cancer, vol. 11, article 184, 2011.

[24] M. Nakada, J. A. Niska, N. L. Tran, W. S. McDonough, and M. E. Berens, "EphB2/R-ras signaling regulates glioma cell adhesion, growth, and invasion," The American Journal of Pathology, vol. 167, no. 2, pp. 565-576, 2005.

[25] Y. Wang, G. Moncayo, P. Morin et al., "Mer receptor tyrosine kinase promotes invasion and survival in glioblastoma multiforme," Oncogene, vol. 32, no. 7, pp. 872-882, 2013.

[26] T. Takino, M. Nakada, H. Miyamori, J. Yamashita, K. M. Yamada, and H. Sato, "CrkI adapter protein modulates cell migration and invasion in glioblastoma," Cancer Research, vol. 63, no. 9, pp. 2335-2337, 2003.

[27] C. A. Lipinski, N. L. Tran, C. Bay et al., "Differential role of proline-rich tyrosine kinase 2 and focal adhesion kinase in determining glioblastoma migration and proliferation," Molecular Cancer Research, vol. 1, no. 5, pp. 323-332, 2003.

[28] K. Kubo, T. Shimizu, S.-I. Ohyama et al., "Novel potent orally active selective VEGFR-2 tyrosine kinase inhibitors: Synthesis, structure-activity relationships, and antitumor activities of $\mathrm{N}$ phenyl-N' -4 -(4-quinolyloxy)phenylureas," Journal of Medicinal Chemistry, vol. 48, no. 5, pp. 1359-1366, 2005.

[29] P. Guo, B. Hu, W. Gu et al., "Platelet-derived growth factor-B enhances glioma angiogenesis by stimulating vascular endothelial growth factor expression in tumor endothelia and by promoting pericyte recruitment," The American Journal of Pathology, vol. 162, no. 4, pp. 1083-1093, 2003.

[30] M. E. Hegi, A.-C. Diserens, P. Bady et al., "Pathway analysis of glioblastoma tissue after preoperative treatment with the EGFR tyrosine kinase inhibitor gefitinib-a phase II trial," Molecular Cancer Therapeutics, vol. 10, no. 6, pp. 1102-1112, 2011.

[31] D. A. Haas-Kogan, M. D. Prados, T. Tihan et al., "Epidermal growth factor receptor, protein kinase $\mathrm{B} / \mathrm{Akt}$, and glioma 
response to erlotinib," Journal of the National Cancer Institute, vol. 97, no. 12, pp. 880-887, 2005.

[32] A. Abulrob, S. Giuseppin, M. F. Andrade, A. McDermid, M. Moreno, and D. Stanimirovic, "Interactions of EGFR and caveolin-1 in human glioblastoma cells: evidence that tyrosine phosphorylation regulates EGFR association with caveolae," Oncogene, vol. 23, no. 41, pp. 6967-6979, 2004.

[33] N. A. Lokker, C. M. Sullivan, S. J. Hollenbach, M. A. Israel, and N. A. Giese, "Platelet-derived growth factor (PDGF) autocrine signaling regulates survival and mitogenic pathways in glioblastoma cells: evidence that the novel PDGF-C and PDGF-D ligands may play a role in the development of brain tumors," Cancer Research, vol. 62, no. 13, pp. 3729-3735, 2002.

[34] H. Raghu, A. K. Nalla, C. S. Gondi, M. Gujrati, D. H. Dinh, and J. S. Rao, "uPA and uPAR shRNA inhibit angiogenesis via enhanced secretion of SVEGFR1 independent of GM-CSF but dependent on TIMP-1 in endothelial and glioblastoma cells," Molecular Oncology, vol. 6, no. 1, pp. 33-47, 2012.

[35] A. Massa, F. Barbieri, C. Aiello et al., "The phosphotyrosine phosphatase $\eta$ mediates somatostatin inhibition of glioma proliferation via the dephosphorylation of ERK1/2," Annals of the New York Academy of Sciences, vol. 1030, pp. 264-274, 2004.

[36] M. Liu, Y. Yang, C. Wang et al., "The effect of epidermal growth factor receptor variant III on glioma cell migration by stimulating ERK phosphorylation through the focal adhesion kinase signaling pathway," Archives of Biochemistry and Biophysics, vol. 502, no. 2, pp. 89-95, 2010.

[37] M.-J. Park, M.-S. Kim, I.-C. Park et al., "PTEN suppresses hyaluronic acid-induced matrix metalloproteinase- 9 expression in U87MG glioblastoma cells through focal adhesion kinase dephosphorylation," Cancer Research, vol. 62, no. 21, pp. 6318-6322, 2002.

[38] J. N. Contessa, M. S. Bhojani, H. H. Freeze, A. Rehemtulla, and T. S. Lawrence, "Inhibition of N-linked glycosylation disrupts receptor tyrosine kinase signaling in tumor cells," Cancer Research, vol. 68, no. 10, pp. 3803-3809, 2008.

[39] A. Pal, A. Glekas, M. Doubrovin et al., "Molecular imaging of EGFR kinase activity in tumors with ${ }^{124}$ I-Labeled small molecular tracer and positron emission tomography," Molecular Imaging and Biology, vol. 8, no. 5, pp. 262-277, 2006.

[40] M. Puputti, O. Tynninen, P. Pernilä et al., "Expression of KIT receptor tyrosine kinase in endothelial cells of juvenile brain tumors," Brain Pathology, vol. 20, no. 4, pp. 763-770, 2010.

[41] M. R. Stettner, W. Wang, L. B. Nabors et al., "Lyn kinase activity is the predominant cellular Src kinase activity in glioblastoma tumor cells," Cancer Research, vol. 65, no. 13, pp. 5535-5543, 2005.

[42] D. Zagzag, B. Shiff, G. I. Jallo et al., "Tenascin-C promotes microvascular cell migration and phosphorylation of focal adhesion kinase," Cancer Research, vol. 62, no. 9, pp. 2660-2668, 2002.

[43] W.-J. Park, Y. Y. Lim, N. S. Kwon, K. J. Baek, D.-S. Kim, and H.-Y. Yun, "Leucine-rich glioma inactivated 3 induces neurite outgrowth through akt and focal adhesion kinase," Neurochemical Research, vol. 35, no. 5, pp. 789-796, 2010.

[44] M. Sciaccaluga, G. L. Gianfranceschi, S. Rocco et al., "Constitutive phosphorylation of Janus kinase 2 in the GL15 glioblastoma derived human cell line," Oncology Reports, vol. 17, no. 1, pp. 1723, 2007.

[45] A. Shimizu, A. Mammoto, J. E. Italiano Jr. et al., "ABL2/ARG tyrosine kinase mediates SEMA3F-induced RhoA inactivation and cytoskeleton collapse in human glioma cells," The Journal of Biological Chemistry, vol. 283, no. 40, pp. 27230-27238, 2008.

[46] J. Fukai, H. Yokote, R. Yamanaka, T. Arao, K. Nishio, and T. Itakura, "EphA4 promotes cell proliferation and migration through a novel EphA4-FGFR1 signaling pathway in the human glioma U251 cell line," Molecular Cancer Therapeutics, vol. 7, no. 9, pp. 2768-2778, 2008.

[47] D.-P. Liu, Y. Wang, H. P. Koeffler, and D. Xie, "Ephrin-A1 is a negative regulator in glioma through down-reguation of EphA2 and FAK," International Journal of Oncology, vol. 30, no. 4, pp. 865-871, 2007.

[48] X. Zhou, L. Hua, W. Zhang et al., "FRK controls migration and invasion of human glioma cells by regulating JNK/c-Jun signaling," Journal of Neuro-Oncology, vol. 110, no. 1, pp. 9-19, 2012.

[49] E. C. Brantley, L. B. Nabors, G. Y. Gillespie et al., "Loss of protein inhibitors of activated STAT-3 expression in glioblastoma multiforme tumors: implications for STAT- 3 activation and gene expression," Clinical Cancer Research, vol. 14, no. 15, pp. 46944704, 2008.

[50] P. J. Boersema, L. Y. Foong, V. M. Y. Ding et al., "In-depth qualitative and quantitative profiling of tyrosine phosphorylation using a combination of phosphopeptide immunoaffinity purification and stable isotope dimethyl labeling," Molecular and Cellular Proteomics, vol. 9, no. 1, pp. 84-99, 2010.

[51] X. Zhan and D. M. Desiderio, "A reference map of a human pituitary adenoma proteome," Proteomics, vol. 3, no. 5, pp. 699713, 2003.

[52] X. Zhan and D. M. Desiderio, "Spot volume vs. amount of protein loaded onto a gel: a detailed, statistical comparison of two gel electrophoresis systems," Electrophoresis, vol. 24, no. 11, pp. 1818-1833, 2003.

[53] A. Martínez-Ruiz, L. Villanueva, C. G. de Orduña et al., "Snitrosylation of Hsp90 promotes the inhibition of its ATPase and endothelial nitric oxide synthase regulatory activities," Proceedings of the National Academy of Sciences of the United States of America, vol. 102, no. 24, pp. 8525-8530, 2005.

[54] H. L. Forsythe, J. L. Jarvis, J. W. Turner, L. W. Elmore, and S. E. Holt, "Stable association of HSP90 and p23, but not HSP70, with active human telomerase," The Journal of Biological Chemistry, vol. 276, no. 19, pp. 15571-15574, 2001.

[55] J. Yang, S. M. Roe, M. J. Cliff et al., "Molecular basis for TPR domain-mediated regulation of protein phosphatase 5," The EMBO Journal, vol. 24, no. 1, pp. 1-10, 2005.

[56] A. Chadli, J. D. Graham, M. G. Abel et al., "GCUNC-45 is a novel regulator for the progesterone receptor/hsp90 chaperoning pathway," Molecular \& Cellular Biology, vol. 26, no. 5, pp. 17221730, 2006

[57] M. Retzlaff, M. Stahl, H. C. Eberl et al., "Hsp90 is regulated by a switch point in the C-terminal domain," EMBO Reports, vol. 10, no. 10, pp. 1147-1153, 2009.

[58] M. Sciacovelli, G. Guzzo, V. Morello et al., "The mitochondrial chaperone TRAP1 promotes neoplastic growth by inhibiting succinate dehydrogenase," Cell Metabolism, vol. 17, no. 6, pp. 988-999, 2013.

[59] L. Zhang, P. Karsten, S. Hamm et al., "TRAP1 rescues PINK1 loss-of-function phenotypes," Human Molecular Genetics, vol. 22, no. 14, Article ID ddt132, pp. 2829-2841, 2013.

[60] S. Yoshida, S. Tsutsumi, G. Muhlebach et al., "Molecular chaperone TRAP1 regulates a metabolic switch between mitochondrial respiration and aerobic glycolysis," Proceedings of the National 
Academy of Sciences of the United States of America, vol. 110, no. 17, pp. E1604-E1612, 2013.

[61] M. H. Baumann, T. Wisniewski, E. Levy, G. T. Plant, and J. Ghiso, "C-terminal fragments of $\alpha$-and $\beta$-tubulin form amyloid fibrils in vitro and associate with amyloid deposits of familial cerebral amyloid angiopathy, British type," Biochemical and Biophysical Research Communications, vol. 219, no. 1, pp. 238242, 1996.

[62] K. Rogowski, F. Juge, J. van Dijk et al., "Stable association of HSP90 and p23, but not HSP70, with active human telomerase," Cell, vol. 137, no. 6, pp. 1076-1087, 2009.

[63] K.-W. Chang, P.-Y. Yang, H.-Y. Lai, T.-S. Yeh, T.-C. Chen, and C.T. Yeh, "Identification of a novel actin isoform in hepatocellular carcinoma," Hepatology Research, vol. 36, no. 1, pp. 33-39, 2006.

[64] H. Kosako, M. Amano, M. Yanagida et al., "Phosphorylation of glial fibrillary, acidic protein at the same sites by cleavage furrow kinase and Rho-associated kinase," The Journal of Biological Chemistry, vol. 272, no. 16, pp. 10333-10336, 1997.

[65] J. A. Read, V. J. Winter, C. M. Eszes, R. B. Sessions, and R. L. Brady, "Structural basis for altered activity of M- and H-isozyme forms of human lactate dehydrogenase," Proteins, vol. 43, no. 2, pp. 175-185, 2001.

[66] Y. M. Gu, Y. H. Jin, J. K. Choi, K. H. Baek, C. Y. Yeo, and K. Y. Lee, "Protein kinase A phosphorylates and regulates dimerization of 14-3-3 epsilon," FEBS Letters, vol. 580, no. 1, pp. 305-310, 2006.

[67] N. Bogdanova, J. Horst, M. Chlystun et al., "A common haplotype of the annexin A5 (ANXA5) gene promoter is associated with recurrent pregnancy loss," Human Molecular Genetics, vol. 16, no. 5, pp. 573-578, 2007.

[68] M. Ritter, C. Buechler, A. Boettcher et al., "Cloning and characterization of a novel apolipoprotein A-I binding protein, AI-BP, secreted by cells of the kidney proximal tubules in response to HDL or apoA-I," Genomics, vol. 79, no. 5, pp. 693$702,2002$.

[69] J. Rush, A. Moritz, K. A. Lee et al., "Immunoaffinity profiling of tyrosine phosphorylation in cancer cells," Nature Biotechnology, vol. 23, no. 1, pp. 94-101, 2005.

[70] V. Pancholi, "Multifunctional $\alpha$-enolase: its role in diseases," Cellular and Molecular Life Sciences, vol. 58, no. 7, pp. 902-920, 2001.

[71] C. Serra-Pagès, Q. G. Medley, M. Tang, A. Hart, and M. Streuli, "Liptins, a family of LAR transmembrane protein-tyrosine phosphatase-interacting proteins," The Journal of Biological Chemistry, vol. 273, no. 25, pp. 15611-15620, 1998.

[72] K. Miura, K. M. Jacques, S. Stauffer et al., "ARAP1: a point of convergence for arf and rho signaling," Molecular Cell, vol. 9, no. 1, pp. 109-119, 2002.

[73] S. C. Moser, D. Bensaddek, B. Ortmann et al., "PHD1 links cellcycle progression to oxygen sensing through hydroxylation of the centrosomal protein Cep192," Developmental Cell, vol. 26, no. 4, pp. 381-392, 2013.

[74] A. Sakurai, J. Gavard, Y. Annas-Linhares et al., "Semaphorin $3 \mathrm{E}$ initiates antiangiogenic signaling through plexin $\mathrm{D} 1$ by regulating Arf6 and R-Ras," Molecular and Cellular Biology, vol. 30, no. 12, pp. 3086-3098, 2010.

[75] H. Daub, J. V. Olsen, M. Bairlein et al., "Kinase-selective enrichment enables quantitative phosphoproteomics of the kinome across the cell cycle," Molecular Cell, vol. 31, no. 3, pp. 438-448, 2008.

[76] X. Huang, W. Yuan, W. Huang et al., "ZNF569, a novel KRABcontaining zinc finger protein, suppresses MAPK signaling pathway," Biochemical and Biophysical Research Communications, vol. 346, no. 3, pp. 621-628, 2006.

[77] L. Peleg, F. Meltzer, M. Karpati, and B. Goldman, "GM2 gangliosidosis B1 variant: biochemical and molecular characterization of hexosaminidase A," Biochemical and Molecular Medicine, vol. 54, no. 2, pp. 126-132, 1995.

[78] M. A. Tischfield, T. M. Bosley, M. A. M. Salih et al., "Homozygous HOXA1 mutations disrupt human brainstem, inner ear, cardiovascular and cognitive development," Nature Genetics, vol. 37, no. 10, pp. 1035-1037, 2005.

[79] H. Le Hir, M. J. Moore, and L. E. Maquat, "Pre-mRNA splicing alters mRNP composition: evidence for stable association of proteins at exon-exon junctions," Genes and Development, vol. 14, no. 9, pp. 1098-1108, 2000. 

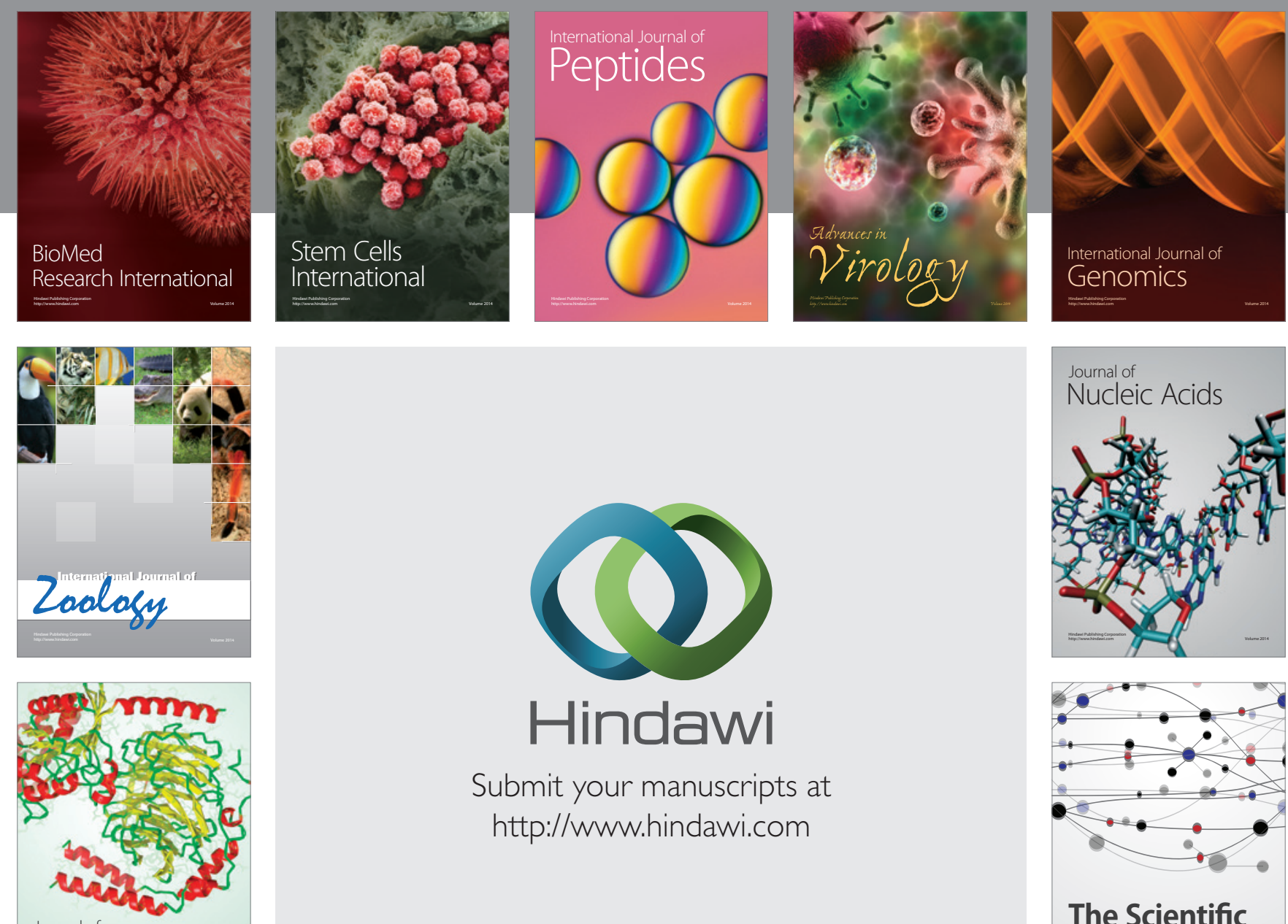

Submit your manuscripts at

http://www.hindawi.com

Journal of
Signal Transduction
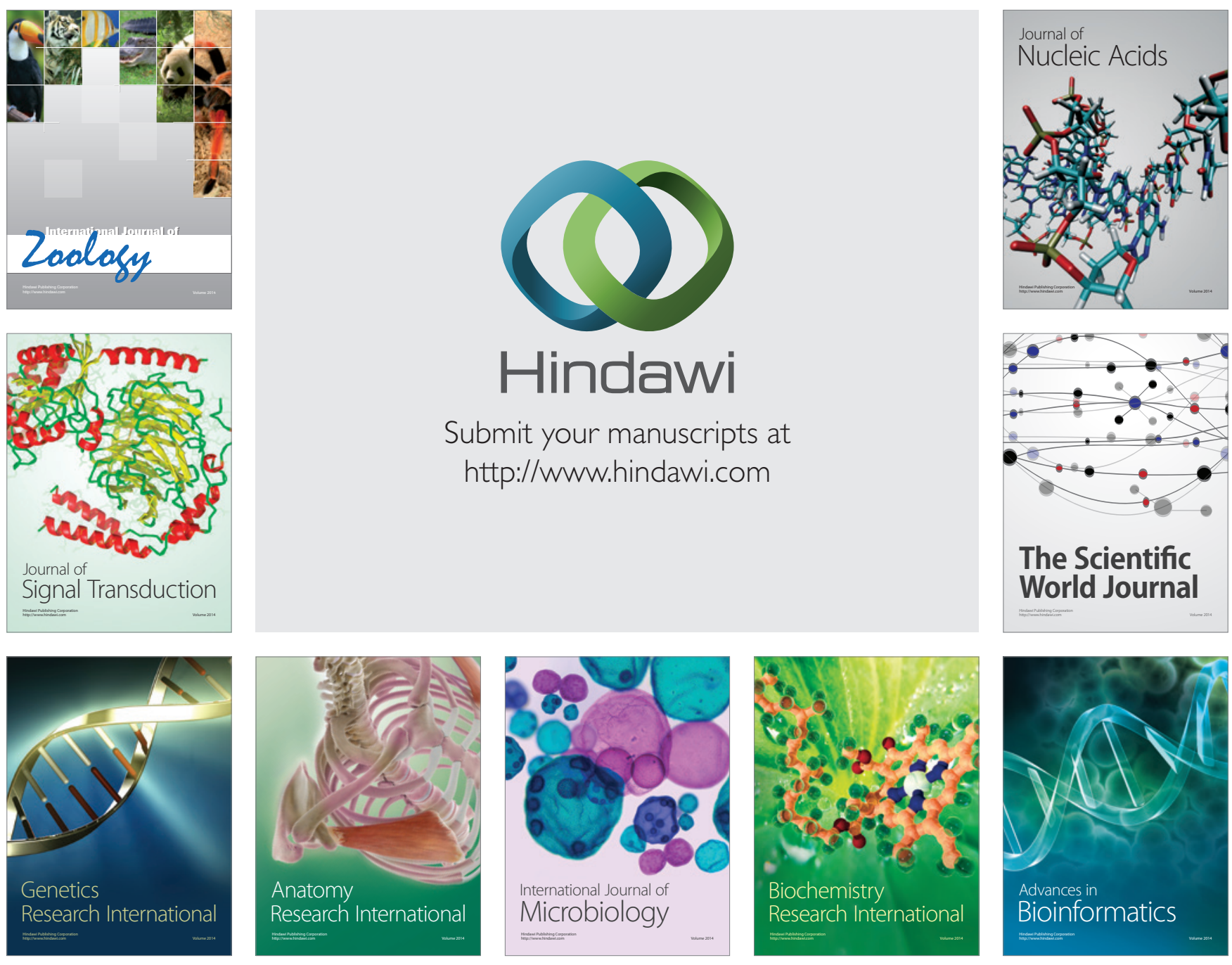

The Scientific World Journal
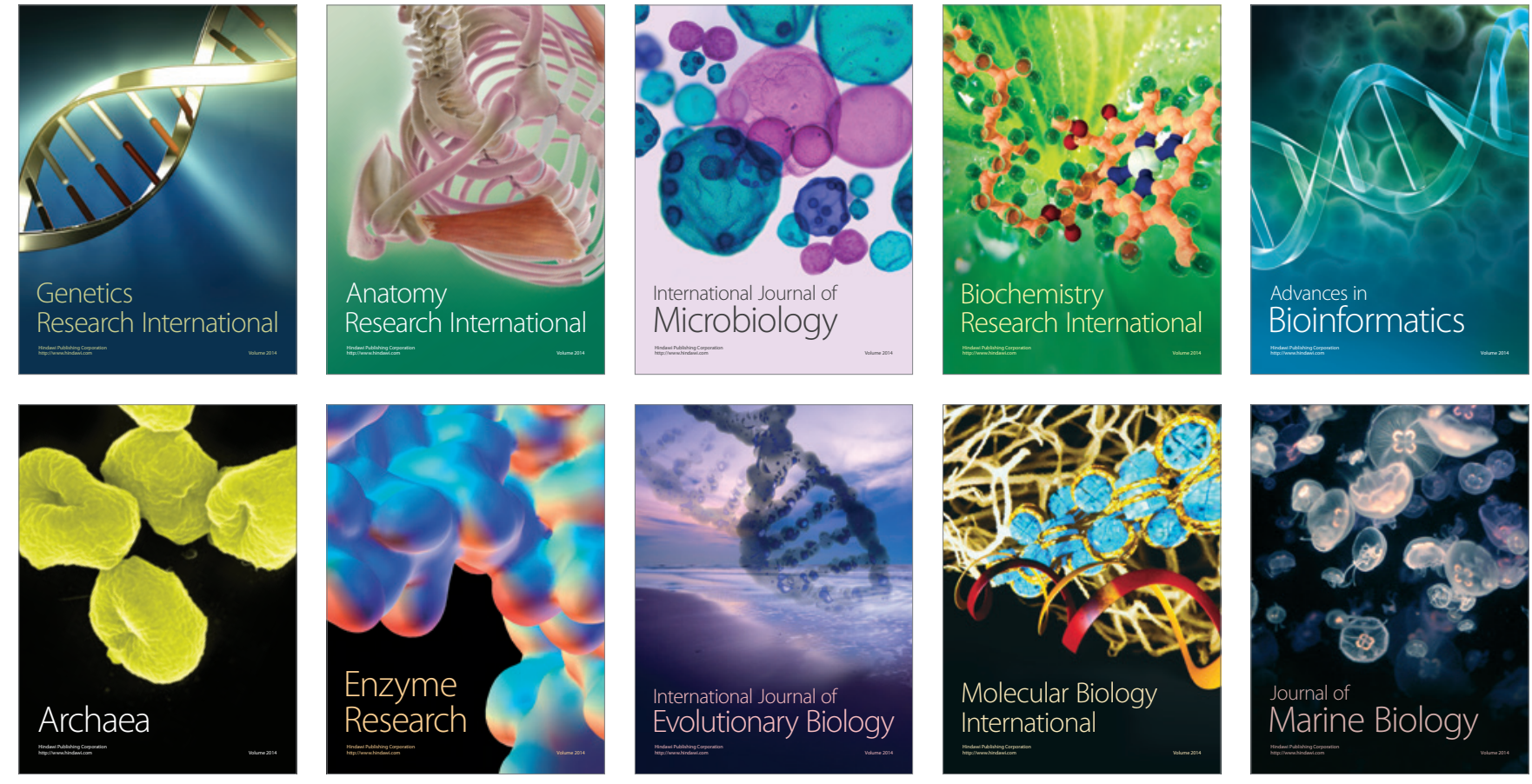